\title{
Snow model comparison to simulate snow depth evolution and sublimation at point scale in the semi-arid Andes of Chile
}

\author{
Annelies Voordendag ${ }^{1, a}$, Marion Réveillet ${ }^{2, b}$, Shelley MacDonell ${ }^{2}$, and Stef Lhermitte ${ }^{1}$ \\ ${ }^{1}$ Department of Geoscience and Remote Sensing, Delft University of Technology, Delft, the Netherlands \\ ${ }^{2}$ Centro de Estudios Avanzados en Zonas Áridas (CEAZA), ULS-Campus Andrés Bello, Raúl Britan 1305, La Serena, Chile \\ ${ }^{a}$ now at: Department of Atmospheric and Cryospheric Sciences (ACINN), University of Innsbruck, Innsbruck, Austria \\ b now at: Univ. Grenoble Alpes, Université de Toulouse, Météo-France, CNRS, CNRM, \\ Centre d'Etudes de la Neige, 38100 Grenoble, France
}

Correspondence: Shelley MacDonell (shelley.macdonell@ ceaza.cl) and Stef Lhermitte (s.lhermitte@tudelft.nl)

Received: 11 January 2021 - Discussion started: 26 January 2021

Revised: 11 August 2021 - Accepted: 12 August 2021 - Published: 7 September 2021

\begin{abstract}
Physically based snow models provide valuable information on snow cover evolution and are therefore key to provide water availability projections. Yet, uncertainties related to snow modelling remain large as a result of differences in the representation of snow physics and meteorological forcing. While many studies focus on evaluating these uncertainties, no snow model comparison has been done in environments where sublimation is the main ablation process. This study evaluates a case study in the semi-arid Andes of Chile and aims to compare two snow models with different complexities, SNOWPACK and SnowModel, at a local point over one snow season and to evaluate their sensitivity relative to parameterisation and forcing. For that purpose, the two models are forced with (i) the most ideal set of input parameters, (ii) an ensemble of different physical parameterisations, and (iii) an ensemble of biased forcing. Results indicate large uncertainties depending on forcing, the snow roughness length $z_{0}$, albedo parameterisation, and fresh snow density parameterisation. The uncertainty caused by the forcing is directly related to the bias chosen. Even though the models show significant differences in their physical complexity, the snow model choice is of least importance, as the sensitivity of both models to the forcing data was on the same order of magnitude and highly influenced by the precipitation uncertainties. The sublimation ratio ranges are in agreement for the two models: $36.4 \%$ to $80.7 \%$ for SnowModel and $36.3 \%$ to $86.0 \%$ for SNOWPACK, and are related to the albedo parameterisation and snow roughness length choice for the two models.
\end{abstract}

\section{Introduction}

Snow models provide valuable information on snow cover evolution and are therefore key to quantify runoff and provide accurate water availability projections. Several models, with different complexities in the representation of different snow processes, from empirical to physically based approaches, have been developed to simulate snow depth changes. Empirical approaches, such as degree-day models (e.g. Braithwaite and Olesen, 1989; Hock, 2003) are based on a simple statistical relationship to positive air temperatures to simulate snow melt. Comparatively, physically based approaches consider all energy flux exchanges at the snow surface by solving the surface energy balance equation (Oke, 2002). The use of the energy balance equation, coupled with snow models, enables a more complete understanding of snow physical processes and are essential for understanding the interaction between snow cover evolution and climate change.

Physically based snow models have different complexities in their physical representations, from a single layer approach (e.g. Strasser and Marke, 2010) to more sophisticated multi-layer detailed models representing the evolution of snow microstructure and the layering of snow physical properties (e.g. Bartelt and Lehning, 2002; Vionnet et al., 2012), leading to a wide variety of snow models with a wide variety of parameterisations. In a snow model intercomparison study, Etchevers et al. (2004) highlighted the importance of parameterisation choice, especially regarding the net longwave and 
albedo characterisation. After comparing 33 snow models, Rutter et al. (2009) concluded that no universal "best" model exists and model performance mainly depends on the study site. Furthermore, the Earth System Model - Snow Model Intercomparison Project (ESM-SnowMIP) compared several snow models to improve the models in the context of localand global-scale modelling (Krinner et al., 2018) and indicated scientific and human errors in snow model intercomparisons (Menard et al., 2021), but the study sites did not include semi-arid regions.

In addition to the development of new models, many studies have focused on model improvements offering different parameterisations in a single model (e.g. Douville et al., 1995; Dutra et al., 2010; Essery, 2015). In such frameworks, many parameters need to be calibrated and are often difficult to be set according to local measurements, such as the albedo and aerodynamic roughness length (Brock et al., 2000, 2006). To address this issue, and to consider and quantify parameter uncertainty propagation in simulated snow depth changes, recent studies have started to use ensemble approaches. Here, models are evaluated based on different likely combinations of values of variables such as snow albedo, snow compaction, fresh snow density, and liquid water transport (e.g. Essery et al., 2013; Lafaysse et al., 2017; Günther et al., 2019).

In addition, forcing data uncertainty has a significant influence on the simulated snow depth changes (e.g. Magnusson et al., 2015; Raleigh et al., 2015; Günther et al., 2019) and needs to be considered in model evaluations. While pointscale simulations forced by direct observations generally reduce forcing uncertainties, measurement errors can be considerable due to the complexity of both measuring certain parameters as well as maintaining measurement sites (e.g. for precipitation (MacDonald and Pomeroy, 2007; Smith, 2007; Wolff et al., 2015) and sensor inclination (Weiser et al., 2016) or sensor failure). Methods such as stochastic perturbation with random noise (e.g. Charrois et al., 2016) or following a uniform or normally distributed bias with different magnitudes (e.g. Raleigh et al., 2015) can be used to build an ensemble of meteorological forcing and explicitly simulate the impact of forcing uncertainty on the simulated snow depth (e.g. Charrois et al., 2016; Zolles et al., 2019; Günther et al., 2019).

Despite past efforts to improve snow models and quantify uncertainty propagation, the uncertainties regarding snow physics representation and meteorological forcing remain (e.g. Essery et al., 2013; Raleigh et al., 2015; Günther et al., 2019), in particular in regions where sublimation is the main ablation process, due to the lack of snow modelling studies in semi-arid regions (Gascoin et al., 2013; Réveillet et al., 2020; MacDonell et al., 2013a; Mengual Henríquez, 2017).

This study aims to evaluate two physical snow models with different complexities, considering parameterisation and forcing uncertainties. We simulate snow depth changes in the semi-arid Andes of Chile using data from an automated weather station. In this region, snow model uncertainty is a key concern as snow melt is an essential water resource for the population (Favier et al., 2009). Despite the importance of snow as water resource, quantifying and understanding the snow cover evolution remains limited and challenging due to (i) high sublimation rates related to high levels of incoming solar radiation, cold air temperatures, arid atmosphere, and high wind speeds (e.g. MacDonell et al., 2013a; Réveillet et al., 2020) and (ii) shallow snow depths due to very low precipitation amounts (Scaff et al., 2017; Réveillet et al., 2020; Ayala et al., 2017). In previous studies, Gascoin et al. (2013) assessed the effect of wind transport on snow cover in the semi-arid Andes using numerical simulations with SnowModel (Liston and Elder, 2006b) and highlighted the significant importance of blowing snow sublimation. They also evidenced the difficulty of the model to capture the small-scale snow depth spatial variability, which was partly related to the lack of reliable input data such as precipitation. Réveillet et al. (2020) indicated that ablation is dominated by sublimation in the semi-arid Andes and that the sublimation ratio increases with elevation. They also quantified a similar proportion of sublimation ratio for two years with contrasting climatic conditions (i.e. dry versus wet), but pointed out significant uncertainties related to the forcing. The study performed by Mengual Henríquez (2017) assessed the snow types in different Chilean regions with SNOWPACK (Bartelt and Lehning, 2002; Lehning et al., 2002a, b) and mainly found that SNOWPACK is a powerful snow model, but an improvement of the forcing data is needed to improve simulations. Despite these previous studies, an accurate assessment of different snow models' sensitivity to parameterisation choice or input forcing is currently missing, although it is expected to have a large impact.

In this work, the sensitivity of SnowModel and SNOWPACK, the common snow models previously used in this region, is assessed based on parameterisation choices and forcing uncertainty. First, the models are calibrated similarly to allow later comparisons and a most ideal setup for both models is designed to acquire a precipitation data set that corrects for the underestimation of precipitation. Second, both models are run with different combinations of parameterisations to assess the uncertainty of parameterisations. Subsequently, forcing uncertainty propagation in the snow model is considered by running the models with 1000 sets of perturbed forcing. The combination of sensitivity analysis to model parameterisations and meteorological forcing allows for the evaluation and comparison of the two models.

\section{Study area and data}

We assess the sensitivity of both models using data from an automatic weather station (AWS) over the snow season of 2017. First, this study area and the meteorological observa- 
tions are described, followed by the data preprocessing procedure.

\subsection{Study area}

The study area is located in the La Laguna catchment in the Chilean Coquimbo region, close to the Argentinian border (Fig. 1a). To assess the sensitivity of the models to the representation of snow physics and meteorological forcing, we use data from the Tapado AWS, a permanent meteorological tower since 2009 located close to the terminus of the Tapado Glacier at $30^{\circ} \mathrm{S}, 69^{\circ} \mathrm{W} ; 4306 \mathrm{~m}$ a.s.l. (Fig. 1c). The site shows a complex topographic setting with average (maximum) wind speeds of $4.2 \mathrm{~m} \mathrm{~s}^{-1}\left(>15 \mathrm{~m} \mathrm{~s}^{-1}\right)$ in 2017 and little precipitation $\left(<200 \mathrm{~mm} \mathrm{a}^{-1}\right)$ that falls as snow during fewer than 10 events per year. Precipitation events mainly occur during the winter season (> 90\%) (Rabatel et al., 2011; Réveillet et al., 2020). Therefore the area surrounding the AWS is only covered with snow in austral winter. At this elevation, vegetation is extremely sparse.

\subsection{Meteorological observations}

The meteorological forcing data consisted of hourly mean values of air temperature (TA), relative humidity (RH), incoming shortwave radiation $\left(S_{\downarrow}\right)$, incoming longwave radiation $\left(L_{\downarrow}\right)$, wind speed (WS), wind direction (WD), and air pressure (PA) measured by the AWS (Figs. 1b, 2, Table 1). Precipitation forcing $(P)$ consisted of hourly data by a Geonor rain gauge (Fig. 1b). This gauge is an unshielded, unheated weighing bucket precipitation gauge filled with antifreeze liquid and oil to prevent freezing and evaporation, respectively. During the snow season, defined as the period with snow on the ground (i.e. between 10 May and 6 November 2017), the station recorded meteorological observations continuously except for the TA and RH, for which gaps have been filled using three nearby AWSs (Fig. 1c, Sect. 2.3).

Hourly snow depth (SD), reflected shortwave radiation $\left(S_{\uparrow}\right)$, and six-hourly means of snow water equivalent (SWE) were also recorded at the station and used for model calibration and evaluation. SWE was measured with a CS725 sensor by Campbell Scientific, which passively detects the change in naturally emitted terrestrial gamma radiation from the ground after it passes through snow cover. It provided two independent SWE observations measuring both potassium and thallium gamma rays (Wright, 2011). The uncertainty given by the manufacturer is $\pm 15 \mathrm{~mm}$ from 0 to $300 \mathrm{~mm}$ and $\pm 15 \%$ from 300 to $600 \mathrm{~mm}$, but differences of up to $82 \mathrm{~mm}$ w.e. between potassium and thallium gamma ray measurements at $\sim 300 \mathrm{~mm}$ w.e. were measured. The manufacturer suggests that the output with the higher count is generally the most reliable, which were the potassium gamma rays measurements (Kevin L. Randall, Campbell Scientific Web Request (case:83574), personal communication, 2018).
We display both data sets and estimate an uncertainty of $\pm 25 \mathrm{~mm}$ for this data set.

\subsection{Preprocessing of forcing data}

The period between 5 May and 30 November 2017 has been covered to model the snow evolution in the austral winter, as this was a season where SWE data were available to validate the models. Since continuous data are required for both snow models, preprocessing was necessary to fill the gaps in the TA and RH data sets (23 June, 11:00, to 31 October, 10:00 CLT, due to sensor failure) and to correct the wind-induced undercatch in the precipitation data. Therefore, TA and RH data were interpolated based on lapse rates from nearby AWSs (Agua Negra (4774 m a.s.1.), Llano de las Liebres (3565 m a.s.l.), and La Laguna (3209 m a.s.1.; Fig. 1c).

For TA, a daily temperature lapse rate (Blandford et al., 2008) was calculated using TA measured at La Laguna and Paso Agua Negra AWSs (1565 m elevation difference) between 2014 and 2017. We fitted a sinusoidal trend over these lapse rates for the four-year period and found daily lapse rates with a maximum of $-6.9^{\circ} \mathrm{C} \mathrm{km}^{-1}$ in winter and a minimum of $-8.0^{\circ} \mathrm{C} \mathrm{km}^{-1}$ in summer. These daily lapse rates were subsequently applied to TA observations of Llano de las Liebres AWS, which is the only AWS that covers the entire period of missing data in 2017. For RH a similar approach was applied using the lapse rate of the daily dew point temperature between the Paso Agua Negra and La Laguna AWSs and applying it to data measured at the Llano de las Liebres AWS. Dew point temperature was converted to RH following Liston and Elder (2006a). Evaluation of this lapse rate interpolation, based on 1638 overlapping observations at Tapado, shows an uncertainty (i.e. RMSE) of $2.8^{\circ} \mathrm{C}$ and $9.97 \%$ for TA and RH, respectively.

Since the precipitation observations were directly influenced by wind, an undercatch in the precipitation gauge is likely (e.g. MacDonald and Pomeroy, 2007; Smith, 2007; Wolff et al., 2015). As there are different possibilities to correct for this, the assimilation and correction of precipitation data are explained in Sect. 3.2.2.

\section{Methods}

\subsection{Model descriptions}

\subsubsection{SNOWPACK}

SNOWPACK was developed by the Swiss Federal Institute (SLF) for Snow and Avalanche Research (Bartelt and Lehning, 2002; Lehning et al., 2002a, b). It is a onedimensional model, but can be implemented in the spatially distributed, three-dimensional snow cover and Earth surface model Alpine3D (Lehning et al., 2006). SNOWPACK includes the $M e t e o I O$ preprocessing library for meteorological 

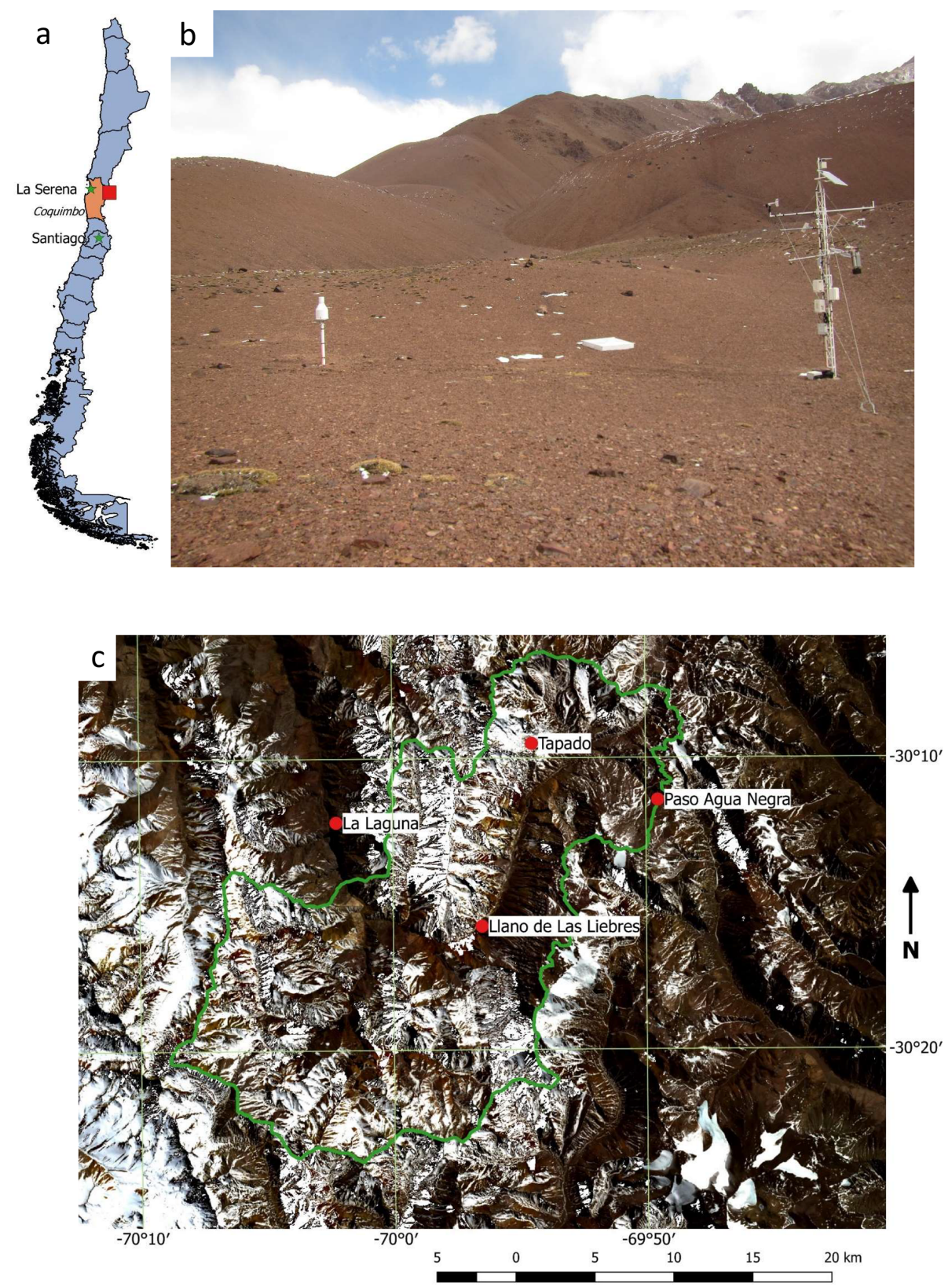

Figure 1. (a) Map of Chile with the Coquimbo Region (orange) and the study area location (red box). (b) Tapado AWS on 26 April 2018 showing the Geonor precipitation gauge (left), which is $10 \mathrm{~m}$ from the central mast of the AWS (right). (c) Map of the borders of the La Laguna catchment (green) with the AWS locations (red points). Landsat 8 images of 29 August 2017 are used as the background and the maps and photo were made by Annelies Voordendag.

data (Bavay and Egger, 2014), which was not used, as we implemented a homogeneous preprocessing approach for both models (see Sect. 2.3). SNOWPACK is a physically based model that has the ability to simulate snow physical properties (e.g. snowpack temperature, layer thickness, snow microstructure, and density) and snow processes (e.g. refreezing, sublimation, melt, and evaporation) for multiple layers, which are merged if layers become too thin. Sublimation and evaporation are calculated for the top element of the snow- pack and melt is simulated using a water transport bucket scheme. In this bucket scheme, all the liquid water exceeding a threshold water content is transported downward in the snowpack or soil (Wever et al., 2014). An extensive description of the model can be found in Bartelt and Lehning (2002) and Lehning et al. (2002a, b). 
Table 1. Available observations, sensor height from the ground, and the manufacturers and type of the corresponding sensor at Tapado AWS.

\begin{tabular}{llrll}
\hline Measurement & Unit & Height $(\mathrm{m})$ & Brand/type & Uncertainty given by manufacturer \\
\hline Accumulated precipitation $(P)$ & $\mathrm{mm}$ & 1.5 & Geonor/T-200B $1000 \mathrm{~mm}$ & $0.1 \%$ full scale \\
Air pressure (PA) & $\mathrm{hPa}$ & 3.5 & Vaisala/PTB110 & $\pm 1.0 \mathrm{hPa}$ \\
Air temperature (TA) & ${ }^{\circ} \mathrm{C}$ & 3.5 & Vaisala/HMP45C & $\pm 0.3^{\circ} \mathrm{C}$ at $0^{\circ} \mathrm{C}$ \\
Incoming LW radiation $\left(L_{\downarrow}\right)$ & $\mathrm{W} \mathrm{m}^{-2}$ & 3.5 & Kipp and Zonen/CNR4 & $10 \%(95 \%$ confidence level) \\
Incoming SW radiation $\left(S_{\downarrow}\right)$ & $\mathrm{W} \mathrm{m}^{-2}$ & 3.5 & Kipp and Zonen/CNR4 & $5 \%(95 \%$ confidence level) \\
Outgoing LW radiation $\left(L_{\uparrow}\right)$ & $\mathrm{W} \mathrm{m}^{-2}$ & 3.5 & Kipp and Zonen/CNR4 & $10 \%(95 \%$ confidence level) \\
Reflected SW radiation $\left(S_{\uparrow}\right)$ & $\mathrm{W} \mathrm{m}^{-2}$ & 3.5 & Kipp and Zonen/CNR4 & $5 \%(95 \%$ confidence level) \\
Relative humidity (RH) & $\%$ & 3.5 & Vaisala/HMP45C & $\pm 2 \% \mathrm{RH}(0$ to $90 \% \mathrm{RH})$ \\
& & & & $\pm 3 \% \mathrm{RH}(90 \%$ to $100 \% \mathrm{RH})$ \\
& & & & and $\pm 0.05 \% \mathrm{RH} /{ }^{\circ} \mathrm{C}$ \\
& $\mathrm{m} \mathrm{s}-1$ & 5.4 & RM Young/5103 & $\pm 0.3 \mathrm{~m} \mathrm{~s}-1$ \\
Wind speed (WS) & $\circ$ & 5.4 & RM Young/5103 & $\pm 3^{\circ}$ \\
Wind direction (WD) & $\mathrm{m}$ & 3.5 & Campbell/SR50A & $\pm 1 \mathrm{~cm}$ \\
Snow depth (SD) & 3.5 & Campbell/CS725 & $\pm 15 \mathrm{~mm} \mathrm{from} 0$ to $300 \mathrm{~mm}$ \\
Water equivalent (SWE, thallium, Tl) & $\mathrm{mm}$ & & & $\pm 15 \%$ from 300 to $600 \mathrm{~mm}$ \\
& & 3.5 & Campbell/CS725 & $\pm 15 \mathrm{~mm} \mathrm{from} 0$ to $300 \mathrm{~mm}$ \\
Water equivalent (SWE, potassium, K) & $\mathrm{mm}$ & & & $\pm 15 \%$ from 300 to $600 \mathrm{~mm}$ \\
& & & &
\end{tabular}

\subsubsection{SnowModel}

SnowModel is a spatially distributed snowpack evolution modelling system composed of four submodels MicroMet, EnBal, SnowPack, and SnowTran3D (Liston and Elder, 2006b). MicroMet is a preprocessing library for meteorological data interpolation, which was not used in this study as we focused on one location only while we implemented a homogeneous preprocessing approach for both models (see Sect. 2.3). EnBal calculates standard surface energy balance exchanges (Liston and Hall, 1995). SnowModel's SnowPack subroutine is a single or multi-layer (max. six layers) snowpack evolution and runoff model that describes snowpack changes in response to precipitation and melt fluxes defined by MicroMet and EnBal (Liston and Hall, 1995; Liston and Elder, 2006b). In SnowModel, the melted snow is redistributed over the remaining snow depth up to a maximum density threshold of $550 \mathrm{~kg} \mathrm{~m}^{-3}$. Any additional melt water is added to the runoff. In this study the model was run with the maximum of snow layers (i.e. six layers) to be comparable with the multiple amount of layers in SNOWPACK. Finally, the three-dimensional model SnowTran3D (Liston and Sturm, 1998), which simulates snow erosion and deposition, is not activated in this study; this choice is discussed in Sect. 5.2.

\subsection{Model setup and sensitivity analysis}

To assess the sensitivity of both models to parameterisation choice and input uncertainty, we applied a four-step approach. First, we set up both models similarly to allow later comparisons (Sect. 3.2.1). Second, we designed the most ideal setup for both models to acquire a precipitation data set that corrects for the underestimation of precipitation. Third, we varied the parameterisation settings of each model to determine the effect of parameterisation choice (Sect. 3.2.3). Last, we implemented forcing biases (Sect. 3.2.4) to evaluate the sensitivity of the models to the meteorological forcing uncertainties. The combination of sensitivity analysis to model parameterisations and meteorological forcing allowed the evaluation and comparison of the two models (Sect. 3.3).

\subsubsection{Parameter values used in both models}

Initially, both models were set up using similar parameters to facilitate intercomparison. These parameters were derived from observations or previous studies (Table 2). For example, the soil albedo was set to 0.15 , as this is the observed surface albedo when there is no snow cover. The observed daily albedo is defined as the daily sum of the average hourly $S_{\uparrow}$ divided by the daily sum of average hourly $S_{\downarrow}$ (Fig. 4e and f). In the absence of roughness length measurements, the roughness length of the bare soil is set to $0.020 \mathrm{~m}$, corresponding to the default roughness length of pebbles and rocks in SnowModel. As surface ground temperature measurements are not available, we set it to $-1{ }^{\circ} \mathrm{C}$ in both models, which is the default value in SnowModel and ensures that the fresh snow does not immediately melt.

\subsubsection{Idealised setup}

Preliminary results showed simulated SWE and SD to be more than 2 times lower than the observed SWE. This is caused by an underestimation of the precipitation measurements, as the AWS is placed in a concave area that collects more snow than the Geonor precipitation gauge. This corresponds with research by Grünewald and Lehning (2014) 


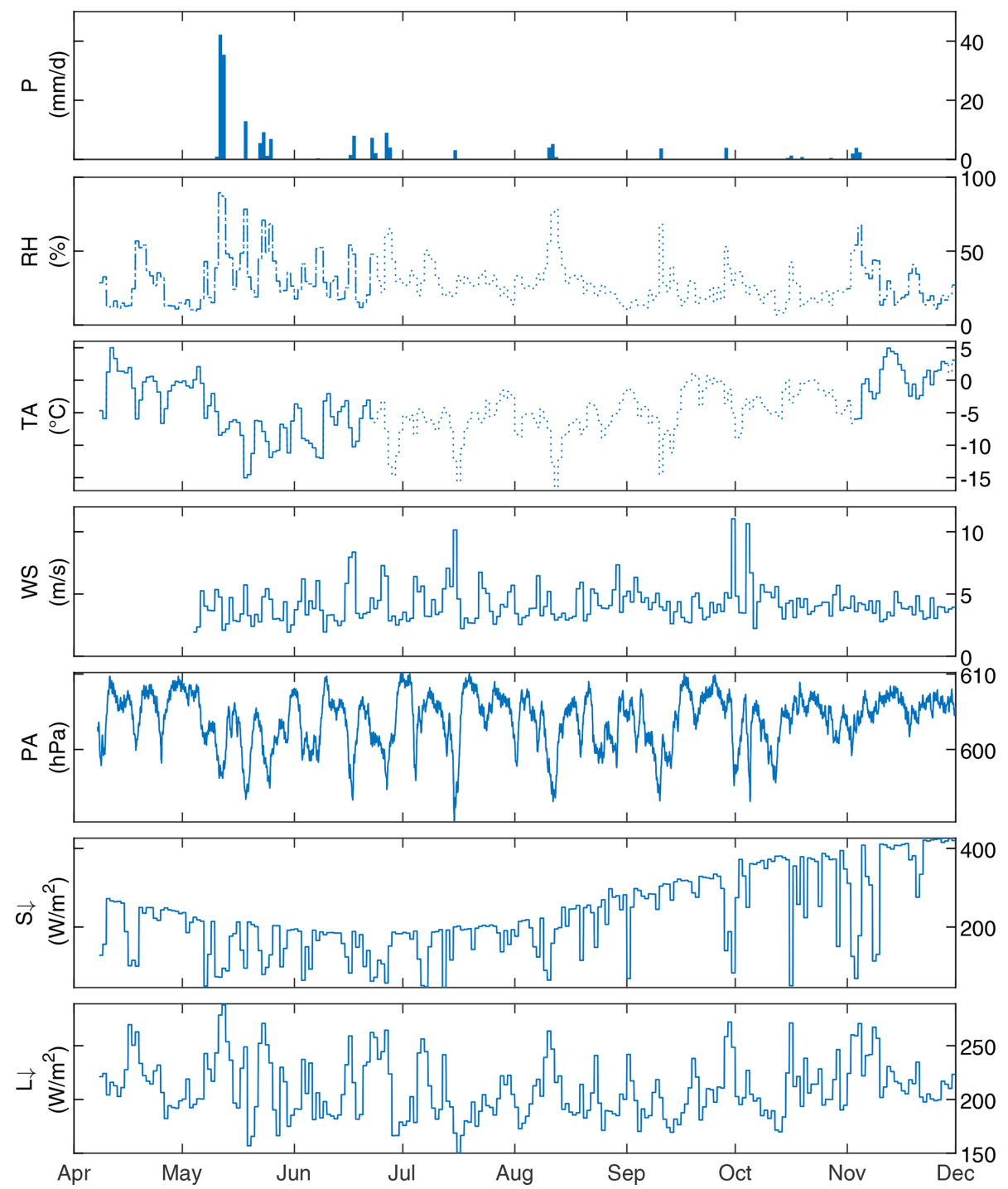

Figure 2. Meteorological observations at Tapado with daily precipitation $(P)$, average daily relative humidity (RH), air temperature (TA), wind speed (WS), air pressure (PA), incoming shortwave radiation $\left(S_{\downarrow}\right)$, and incoming longwave radiation $\left(L_{\downarrow}\right)$ from April to December 2017. Dotted lines indicate the TA and RH interpolations.

on the spatial variability of SD measurements. Therefore, to correct the precipitation used as input for the models, an idealised setup is designed, making use of all the data that the models allow as forcing. Two approaches are designed to adjust the precipitation data set. First, it is chosen to assimilate a precipitation data set, which both models perform in different ways. SNOWPACK assimilates the data if SD is given as input. Reflected SW radiation is also given as input to prevent inaccurate parameterisations of the albedo. The precipitation data set is assimilated with the five possible fresh snow density parameterisations in SNOWPACK. SnowModel allows the possibility to assimilate the precipitation when SWE is given, but is not able to cope with reflected SW radiation as input. Therefore, six ensembles are made out of two albedo and three fresh snow density parameterisations to find an assimilated precipitation data set. Second, the precipitation is reconstructed from the SWE observations, which was computed using the cumulative positive SWE (potassium) changes during precipitation events (detected by the Geonor T-200B). The positive SWE changes beyond precipitation events are not accounted for, as they might originate from deposition caused by snow drift and its inclusion would have resulted in an overestimation in this data set. Hereafter this precipitation data set is called PSWE.

Atmospheric stability and snow roughness length $\left(z_{0}\right)$ are key parameters in semi-arid regions where sublimation is an important process. As SnowModel only allows atmospheric stability corrections based on the Richardson number, we opted for this method and similar roughness lengths in both models to assure intercomparability. The $z_{0}$ was set to both 
Table 2. SNOWPACK and SnowModel parameter characteristics. The possible snow albedo parameterisations and fresh snow density models are described in Sect. S1 in the Supplement.

\begin{tabular}{lll}
\hline & SNOWPACK & SnowModel \\
\hline Soil albedo & 0.15 (calibrated) & 0.15 (calibrated) \\
Max/min snow albedo & None & $0.6 / 0.9$ (calibrated) \\
Atmospheric stability correction model & Richardson number & Richardson number (default) \\
Roughness length (soil) & $0.02 \mathrm{~m}$ & $0.02 \mathrm{~m}$ (default) \\
Roughness length (snow) & $0.001 \mathrm{~m}$ and $0.01 \mathrm{~m}$ & 0.001 and $0.01 \mathrm{~m}$ \\
Surface ground temperature & $-1^{\circ} \mathrm{C}$ & $-1^{\circ} \mathrm{C}$ (default) \\
Thermal conductivity & Default & Multilayer subroutine \\
Wind erosion/snow transport by wind & Off & Off \\
Maximum number of snow layers & Unlimited & Six layers \\
Fresh snow density parameterisations & Five options & One default option and two from SNOWPACK \\
Albedo parameterisations & Six options, four used & Two options \\
Simulated ablation processes & Sublimation, runoff, evaporation & Sublimation, runoff \\
Water transport in snowpack & Bucket scheme (default) & Default \\
\hline
\end{tabular}

0.001 and $0.01 \mathrm{~m}$. The former, $0.001 \mathrm{~m}$, is based on an earlier sensitivity study (Réveillet et al., 2020) and unpublished eddy covariance measurements (MacDonell et al., 2013a); $0.01 \mathrm{~m}$ is based on literature (e.g Brock et al., 2006; Cuffey and Paterson, 2010). The first and second approach of the idealised setup are both tested with $z_{0}$ of $0.001 \mathrm{~m}$ and $0.01 \mathrm{~mm}$; thus, the idealised setup in total consists of four cases for each five (SNOWPACK) or six (SnowModel) simulations.

This idealised case therefore corresponds to simulations using the best possible combination of input data. As such observations are not always available or used to evaluate models, the idealised simulations are not used for the sensitivity study and model comparisons, which are based on optimal simulations (i.e. without assimilating precipitation and albedo; see Sect. 3.2.3). The simulated SWE and SD are compared to the observed SWE and SD and the assimilated precipitation data sets are shown in Fig. 3. Due to complexities with the assimilated precipitation data and the need for SWE as validation data, the precipitation data set $\left(P_{\text {cor }}\right)$ that is used in the further study is based on a wind correction by Wolff et al. (2015) (see Sect. 4.1).

\subsubsection{Sensitivity analysis of variable parameterisations}

To assess the impact of the parameterisations on the snowpack simulation, an ensemble approach based on different combinations of albedo and snow density parameterisations and $z_{0}$ was used (e.g. Essery et al., 2013; Lafaysse et al., 2017, and Sect. 3.2.2). The choice to limit the sensitivity tests to these three parameters is discussed in Sect. 5.2.

For SNOWPACK, 40 runs were performed over the 2017 season based on four different albedo, five fresh snow density parameterisations, and two different $z_{0}$ values. Each of the albedo parameterisations is based on empirical relations derived from continuous observations at Weissfluhjoch (Lehn- ing et al., 2002a) or on grain size (Schmucki et al., 2014), while the fresh snow parameterisations are empirical formulas depending on the TA, RH, WS, and surface temperature. More details are found in Sect. S1 in the Supplement and references therein.

For SnowModel, an ensemble of 12 simulations was run, considering two albedo, three snow density parameterisations, and two different $z_{0}$. The albedo parameterisations range between 0.6 and 0.9 depending on (i) TA solely (more details in Liston and Hall, 1995; Liston and Elder, 2006b; and in Sect. S1 in the Supplement) or (ii) on TA and time (Strack et al., 2004, and Sect. S1). SnowModel's default fresh snow density parameterisation depends on the wet bulb temperature, but we included two fresh snow density parameterisations from SNOWPACK depending on TA, RH, WS, and surface temperature to test the model more extensively. In these additional parameterisations, we preserved the SnowModel defaults for minimum $\left(50 \mathrm{~kg} \mathrm{~m}^{-3}\right)$ and maximum fresh snow density $\left(158.5 \mathrm{~kg} \mathrm{~m}^{-3}\right)$.

Each of the ensemble simulations was forced by the observations (TA, RH, PA, WS, WD, $S_{\downarrow}$, and $L_{\downarrow}$ ) as described in Sect. 2.3 and the $P_{\text {cor }}$ acquired after the idealised setup (Sect. 3.2.2). The simulations are evaluated by comparing the model output of SD, SWE, and albedo with the corresponding observations. Based on this evaluation, the simulation with the lowest RMSE and highest $R^{2}$ between the observed and modelled albedo is chosen as the reference for the forcing sensitivity analysis discussed in Sect. 3.2.4.

\subsubsection{Forcing uncertainty estimation}

To assess the model sensitivity to meteorological measurement uncertainties, a bias has been applied to the meteorological forcing presented in Sect. 2.3 to generate an ensemble of 1000 forcing files. Raleigh et al. (2015) have shown that the model outputs are more sensitive to forcing biases than ran- 
Table 3. Forcing data for the snow models with the corresponding uncertainty $\sigma$ used in the ensemble simulation. The ranges of PA, TA, $S_{\downarrow}$, $L_{\downarrow}$, RH, and WS are ranges as used by Raleigh et al. (2015). The WD range is according to the uncertainty given by the manufacturer and the $P_{\text {cor }}$ range is described in Sect. 3.2.4.

\begin{tabular}{llll}
\hline Forcing & Distribution & Range & Unit \\
\hline Accumulated precipitation $\left(P_{\text {cor }}\right)$ & Uniform & {$[-100,+100]$} & $\mathrm{mm} \mathrm{a}^{-1}$ \\
Air pressure (PA) & Normal & {$[-100,+100]$} & $\mathrm{Pa}$ \\
Air temperature (TA) & Normal & {$[-3.0,+3.0]$} & ${ }^{\circ} \mathrm{C}$ \\
Incoming longwave radiation $\left(L_{\downarrow}\right)$ & Normal & {$[-25,+25]$} & $\mathrm{W} \mathrm{m}^{-2}$ \\
Incoming shortwave radiation $\left(S_{\downarrow}\right)$ & Normal & {$[-100,+100]$} & $\mathrm{W} \mathrm{m}^{-2}$ \\
Relative humidity (RH) & Normal & {$[-0.25,+0.25]$} & $\%$ \\
Wind speed (WS) & Normal & {$[-3,+3]$} & $\mathrm{m} \mathrm{s}^{-1}$ \\
Wind direction (WD) & Normal & {$[-3,+3]$} & $\circ$ \\
\hline
\end{tabular}

dom errors. Therefore, all input variables except $P_{\text {cor }}$ were modified by adding hourly biases with a normal distribution $N\left(\mu=0, \sigma^{2}\right)$ with $\sigma$ being the uncertainty range taken from Raleigh et al. (2015) and reported in Table 3. The biases have been kept within their corresponding range (Table 3) by assuming that $99.7 \%$ of the bias, thus $3 \sigma$, is within this range. This positive component of the range is divided by three and multiplied with a normally distributed random number and added to the observed forcing. We have chosen 1000 runs as a compromise between computational effort and a reliable confidence interval.

The distribution of the precipitation uncertainty is chosen to be uniform, as the observed precipitation was low (i.e. $180.7 \mathrm{~mm}$ w.e. at the end of the season) and the differences between the assimilated precipitation (SnowModel) and PSWE cover approximately $200 \mathrm{~mm}$ w.e. (Sect. 4.1).

Subsequently, based on the perturbed input data, 2000 snow model simulations are performed: 1000 with meteorological biases and 1000 with combined meteorologi$\mathrm{cal} /$ precipitation biases. This setup was chosen to enable the differentiation between meteorological and precipitation uncertainties, which would be difficult in a combined approach where precipitation uncertainty would dominate.

\subsection{Model evaluation}

Model evaluation consists of comparing the model output of SD, SWE, and albedo with the corresponding observations. For the idealised case this consists of evaluating the RMSE and $R^{2}$ between the modelled and the observed SD to acquire precipitation data that approach the correct mass balance. For the parameterisation uncertainty, this consists of evaluating the RMSE and $R^{2}$ between the modelled and the observed albedo to select the best reference for each model (i.e. 40 for SNOWPACK and 12 for SnowModel). In this case, it is chosen to only compare between modelled and observed albedo, as this ensures the best possible net shortwave radiation term in the energy balance equation. The forcing uncertainty is evaluated by comparing the differences of end of snow sea- son. Last, the differences in ablation processes of the parameterisations are shown.

\section{Results}

\subsection{Idealised simulations}

The assimilated precipitation data sets markedly differ between SNOWPACK and SnowModel (blue lines, Fig. 3e and f). For clarity Fig. 3 only shows the results of the idealised simulations for the $z_{0}$ value of $1 \mathrm{~cm}$; the results for $z_{0}$ of $1 \mathrm{~cm}$ and $1 \mathrm{~mm}$ are displayed in Sect. S2. For SNOWPACK, 8 out of 10 runs with $z_{0}=1 \mathrm{~cm}$ crashed, thus only two simulations are shown. The reason for these crashes has not been further investigated.

Assimilation of SD in SNOWPACK results in SWE that approximates the PSWE (Fig. 3), leading to assimilated precipitation amounts of 2.55 to 3.02 times the observed precipitation and a good correspondence with the observed SD (i.e. RMSE between 9.2 and $11.5 \mathrm{~cm}$ and $R^{2}$ between 0.90 and 0.93 , calculated with the observed and simulated SD; Fig. 3a).

Assimilation of SWE in SnowModel only adjusts the precipitation between 22 and 27 June and between 7 and $12 \mathrm{Au}-$ gust. The amount of precipitation is not adjusted at the beginning of the season; thus, the assimilated data by SnowModel still lead to an underestimation of the SD and SWE (Fig. $3 \mathrm{~b}$ and d). The missing adjustment of the SWE is probably caused by SnowModel taking a maximum of 99 SWE observations; the observations do not exactly align with the precipitation events, which leads to correction factors of one (i.e. no change) to the precipitation data. The assimilated precipitation is approx. 1.6 times larger than the observed precipitation and the agreement between modelled and observed SD is better for SNOWPACK than for SnowModel (i.e. RMSE between 7.1 and $17.1 \mathrm{~cm}$ and $R^{2}$ between 0.19 and 0.90 calculated with the observed and simulated SD; Fig. 3b). 

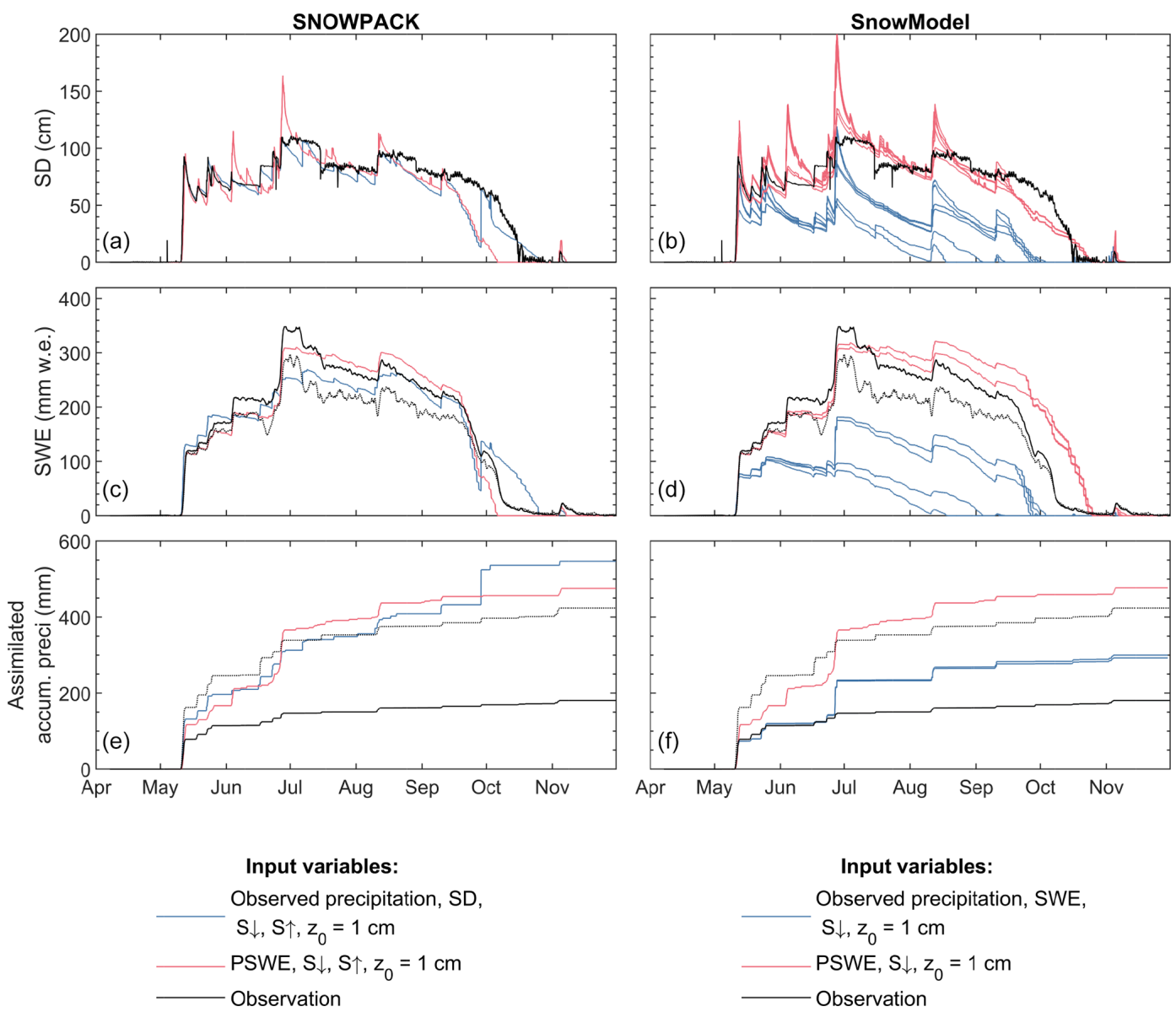

Figure 3. (a, b) SD, (c, d) SWE, and (e, f) the cumulative assimilated precipitation for the simulations with SNOWPACK (a, c, e) and SnowModel $(\mathbf{b}, \mathbf{d}, \mathbf{f})$ and observations (black). The different input variables are given in the legend. The solid (dotted) line in (c) and (d) indicates the more (less) reliable SWE measurement from potassium (thallium) rays (see Sect. 2.3) and the dotted line in (e) and (f) is $P_{\text {cor }}$. The models have assimilated the observed precipitation (black) to the output (red/blue) given in (e) and (f). Only one red and one blue line is shown for SNOWPACK as the other eight simulations crashed. The simulations for $z_{0}=1 \mathrm{~mm}$ are found in Sect. S2.

Both models overestimate the SWE between mid-July and September when PSWE was given as input (red lines in Fig. 3c and d). This is likely caused by an overestimation of the PSWE at the end of June. Only small amounts of precipitation are observed at the precipitation gauge, but the observed SWE distinctly increases probably due to snow drift, as strong winds were also observed. A similar thing occurs at the end of September. The models markedly increase the amount of precipitation (between 97 and $137 \mathrm{~mm}$ w.e.) in the assimilation runs, but only small amounts of precipitation and strong winds were observed. This is related to a strong melt in September, not simulated by the model, along with models trying to get the SWE and SD to the observational levels. The strong melt in September is caused by a sudden decrease of the albedo (observations in Fig. 4e and f), as it is likely that the snow got covered with dust after some days with strong wind at the end of September, but the simulations overestimate the melt caused by this albedo decrease. Likewise, high wind speeds and a strong decrease of SWE and SD are observed mid-July, which is likely due to snow erosion that is not considered in our simulations. The overestimation of and the need for SWE as validation data are indications that the PSWE is not a valid precipitation data set for our simulations, but it is also unfeasible to select one of the assimilated precipitation sets by SNOWPACK as the amount of precipitation markedly increases at the end of September and we want to use SD as validation data.

Therefore, three different precipitation corrections depending on WS (Smith, 2007; MacDonald and Pomeroy, 2007) or on TA and WS (Wolff et al., 2015) were applied to the observed precipitation (see Sect. S3). Equation (12) from Wolff et al. (2015) with WS corrected to gauge height using a logarithmic wind profile (e.g. Lehning et al., 2002a) and $z_{0}$ of $0.01 \mathrm{~m}$ is used as precipitation data $\left(P_{\text {cor }}\right)$ in the further study, as this correction approaches the PSWE and shows an increase in precipitation of 2.35 times the observed precipitation at the end of the season. 


\subsection{Sensitivity analysis of parameterisations}

Evaluation of simulated SD and SWE based on various parameterisations shows that both models are in good agreement with observations (Fig. 4), although they overestimate SWE at the beginning of the season (May/June). The correction of the precipitation with the equation from Wolff et al. (2015) overestimates the precipitation in this period and also leads to an overestimation in the simulations.

For SNOWPACK, the spread of the simulated SD from the 40 different parameterisations (20 simulations for $z_{0}=1 \mathrm{~mm}$ and 20 for $z_{0}=1 \mathrm{~cm}$ ) is the largest at the end of the snow season (i.e. October) (Fig. 4a). The date of snow-free surface is the earliest at 8 October and exceeds the simulated period (i.e. after 30 November), depending on parameterisation choice, and covers the observed date of snow removal (i.e. 16 October). The different SNOWPACK parameterisations (equations in Sect. S1) show a mean SD difference of $32 \mathrm{~cm}$ (which corresponds to $28.9 \%$ of the total SD) between the minimum and maximum simulated SD (Fig. 4a), with a maximum of $127 \mathrm{~cm}$ observed at 27 June. For the SWE, this corresponds to a mean difference of $98.3 \mathrm{~mm}$ w.e. (i.e. $28.2 \%$ of the total SWE) (Fig. 4c). The large modelled SD spread in May and June can be explained by the different density parameterisation choices as it is not apparent in the SWE simulations (Fig. $4 \mathrm{a}$ and c). The rapid decrease $\left(3-8 \mathrm{~cm} \mathrm{~d}^{-1}\right)$ of snow depth until July, caused by compaction of the snowpack, is simulated by the majority of fresh snow density parameterisations, while only one fresh snow density parameterisation models a more moderate compaction (i.e. the bold red line has a moderate slope, compared to the light red lines in Fig. 4a, until July). From July onward, the measured snow depth decreases 10 centimetres per $25 \mathrm{~d}$, which is only simulated by the fresh density parameterisation that simulated moderate compaction before July. Snow density measurements were unavailable in 2017 and the observed snow density in Fig. 4g is calculated with SWE/SD. The observed snow density is only shown until the end of August, as the calculation led to unrealistic decreasing snow densities after August. This is likely caused by higher readings at the SD sensor than at the SWE sensor, as those sensors were placed on different sides of the meteorological tower or to a bias of the SWE sensor in the ablation season as explained by Smith et al. (2017).

The albedo evaluation (Fig. 4e) and corresponding statistics (Sect. S4) highlight one parameterisation choice that outperforms all other parameterisations (i.e. RMSE of $0.09(-)$ and $R^{2}$ of 0.86 calculated with the observed and simulated albedo) in terms of snow compaction after snowfall events, end of snow season, and albedo evolution (Fig. 4e). Therefore this simulation with a $z_{0}$ of $1 \mathrm{~cm}$ is selected as the reference simulation (represented in bold lines in Fig. 4) for the forcing uncertainty simulations.

For SnowModel, the largest SD spread of the 12 ensembles (six for every $z_{0}$; equations in Sect. S1) occurs at the end of the simulated snow season (i.e. August, September, and October) with complete snow removal between 21 October and 12 November (i.e. 22 d) (Fig. 4b). The mean SD difference between the parameterisations is $20 \mathrm{~cm}$ (i.e. $18 \%$ of the total SD), with a maximum of $152 \mathrm{~cm}$ at the first snowfall event (12 May), while for SWE the mean difference is $57 \mathrm{~mm}$ (i.e. $19.2 \%$ of the total SWE) with a maximum of $317 \mathrm{~mm}$ w.e. at 12 August (Fig. 4d).

Quantitative analysis (Sect. S4) shows best performance scores for the time-evolution albedo approach in combination with the reference snow density parameterisation and a $z_{0}$ of $1 \mathrm{~cm}$ (RMSE of $0.150(-)$ and $R^{2}$ of 0.600 ). Therefore, these are used as the reference simulation (bold line in Fig. 4).

Comparison of the SNOWPACK and SnowModel output shows similar SD variations attributed to snow density parameterisations that simulate low density snowfall with notable subsequent compaction (Fig. 3g and h). In reality, this happens at Tapado until June, followed by a different regime with denser fresh snow and less compaction. The biggest difference between the models, however, is the result of the albedo parameterisations. Where SnowModel relies on two albedo models based on TA and albedo ranges, SNOWPACK relies on empirical relations calibrated with measurements in Switzerland and not adapted to the arid Tapado climate. Nevertheless, the albedo of the reference run of SNOWPACK performs well in a semi-arid area. Last, the simulations by SnowModel all approximate the end of snow season within a period of $22 \mathrm{~d}$, whereas the simulations at the end of season noticeably diverge for SNOWPACK. This is likely caused by TA being above the freezing point at the end of October, resulting in a fast melt simulated for all ensembles by SnowModel.

\subsection{Sensitivity analysis of forcing data}

\subsubsection{Excluding precipitation uncertainty}

The biased forcing excluding precipitation uncertainty shows a similar sensitivity for SNOWPACK and SnowModel (Fig. 5a and c) with mean SD/SWE biases of $52 \mathrm{~cm} / 163 \mathrm{~mm}$ w.e. for SNOWPACK and $47 \mathrm{~cm} / 172 \mathrm{~mm}$ w.e. for SnowModel. The simulations with SnowModel show more uncertainty in the melting period (e.g. in October), but otherwise the simulations mainly overlap. The forcing uncertainty results in complete snow removal simulations ranging from 27 August to 28 November (i.e. 93 d) for SNOWPACK and 30 August to 25 November (i.e. $87 \mathrm{~d}$ ) for SnowModel. The reference simulations of both models are located in the middle of the spread of simulations, which is coherent with the normal distribution of the biases applied to the forcing. The biggest differences between the models are found in the way SD has been simulated. The reference run and the 1000 simulations with biased forcing show marked settling rates throughout the season with SnowModel, whereas the settling is more moderate for SNOWPACK. This depends on the cho- 


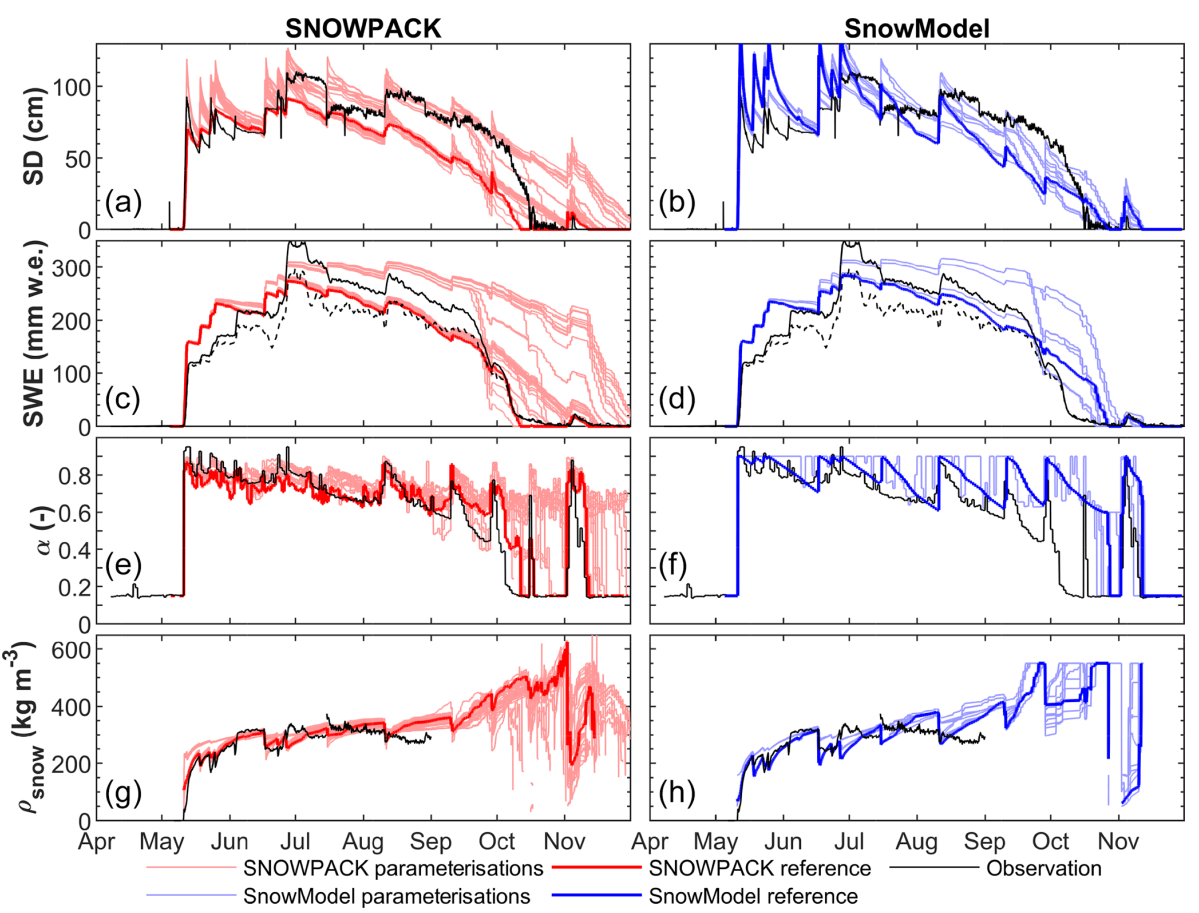

Figure 4. (a, b) SD, (c, d) SWE, (e, f) albedo, and (g, h) snow density simulations (coloured) of the ensemble approaches for SNOWPACK (red), SnowModel (blue), and observations (black). The bold coloured lines show the reference simulations chosen as the most optimal parameterisation set according to the measured albedo. The solid (dotted) line in (c) and (d) indicates the more (less) reliable SWE measurement from potassium (thallium) rays.

sen snow density parameterisation and is discussed further in Sect. 5 .

\subsubsection{Including precipitation uncertainty}

The forcing perturbations including precipitation uncertainty shows that precipitation uncertainty has a large impact on SD and SWE ensemble spread (Fig. 5b and d). Averaged over the season this results in SD/SWE biases of $75 \mathrm{~cm} / 257 \mathrm{~mm}$ w.e. and $70 \mathrm{~cm} / 262 \mathrm{~mm}$ w.e. for SNOWPACK and SnowModel, respectively. Along with the similar average spread over the entire season observed for both models, the range of the simulated days of snow-free surface is also similar; for SnowModel this date ranges between 20 August and 29 November (i.e. $101 \mathrm{~d}$ ) and the range is similar but a bit later in the season for SNOWPACK (i.e. between 29 August and early December). Again, the main differences are found in the settling of the snowpack (see Sect. 5).

\subsection{Impacts of the model choice and parameterisations on sublimation}

Ablation rates (Fig. 6) show that sublimation is the dominant mode of mass loss in both models until September (i.e. cold period), followed by melt from September to the end of the season (i.e. end of November, and called the melting period). Note that for SNOWPACK, the first day of snow-free sur- face of the reference run is 11 October and for SnowModel is 27 October.

For SNOWPACK, the spread of the averaged sublimation rates corresponding to the ensemble runs from the first day of snow to 20 September have a minimum of 1.41 and a maximum of $2.96 \mathrm{~mm}$ w.e. $\mathrm{d}^{-1}$ (Fig. 6a). During the cold period, when no melt occurs, the sublimation amounts mainly depend on the $z_{0}$, with sublimation rates ranging between 1.40 and $3.18 \mathrm{~mm}$ w.e. $\mathrm{d}^{-1}$, but this is mainly clustered according to the implemented $z_{0}$. At the end of the season, the total sublimation ranges between 153 and $364 \mathrm{~mm}$ w.e. (corresponding to $36.2 \%$ to $86.0 \%$ of the total ablation, again strongly depending on the $z_{0}$ ). During the melting period, the ensemble runs show a large spread of melt rates ranging between 0.97 to $17.7 \mathrm{~mm}$ w.e. $\mathrm{d}^{-1}$. The total amount of runoff is between 28.9 and $236 \mathrm{~mm}$ w.e. for SNOWPACK, and this model also simulates evaporation, which contributes between $2.5 \%$ and $10.2 \%$ of total ablation (Fig. 6a).

For SnowModel, sublimation differences between the parameterisations are similar (Fig. 6b) with average sublimation rates from the first day of snow to 20 September ranging between 1.27 and $2.79 \mathrm{~mm}^{\mathrm{m}}$.e. $\mathrm{d}^{-1}$. At the end of the winter season the sublimation totals range between 154 and $342 \mathrm{~mm}$ w.e. (which corresponds to $36.4 \%$ to $80.7 \%$ of the total ablation). The runoff is between 81.7 and $269 \mathrm{~mm}$ w.e. A closer analysis of Fig. 6b shows that SnowModel's output clusters into four groups, where the grouping is determined 


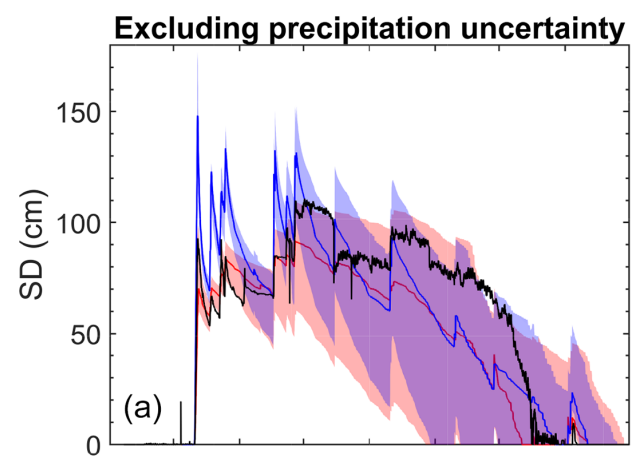

With precipitation uncertainty
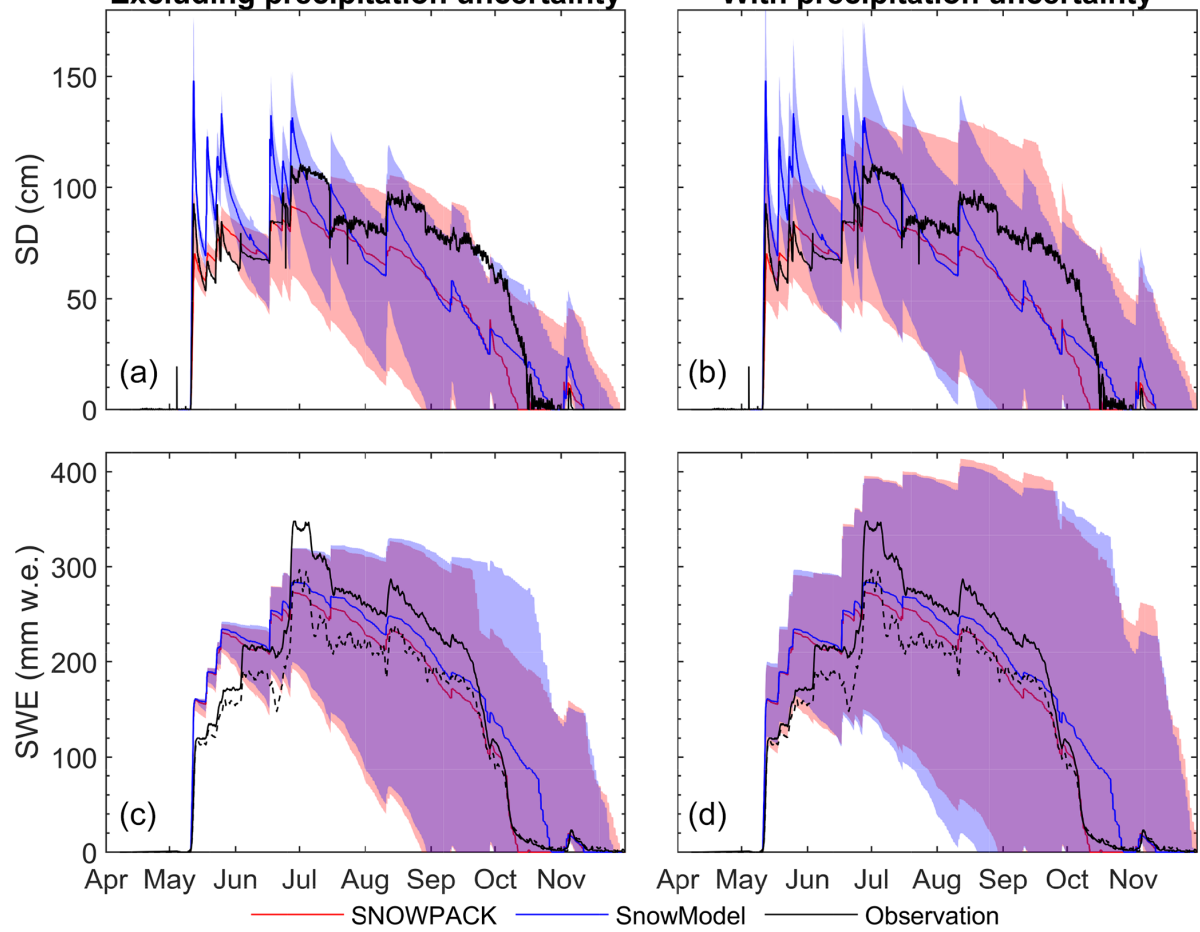

Figure 5. Observed (black) and simulated (colour) SD and SWE by SNOWPACK and SnowModel forced by the 1000 ensembles of meteorological data. The reference run (see Sect. 3.2.3) of both models is the bold coloured curve. The shaded area corresponds to the 1000 runs of (a, b) snow depth and SWE (c, d) of SNOWPACK (red) and SnowModel (blue) for the run with biased forcing. Panels (a)-(c) exclude precipitation uncertainties and (b)-(d) include precipitation uncertainties. The solid (dotted) line in (c) and (d) indicates the more (less) reliable SWE measurement from potassium (thallium) rays.

by the albedo parameterisation and $z_{0}$ with limited influence of fresh snow density parameterisations. The two lower clusters are linked to the $z_{0}$ value of $1 \mathrm{~mm}$. The differences between clusters for different $z_{0}$ values increase as the difference in albedo between the parameterisations increase at the end of June.

While the ensemble parameterisation simulations do not lead to significant differences in the modelled end date of the snow season (i.e. difference of $22 \mathrm{~d}$ ), the albedo parameterisation and $z_{0}$ value directly impact the proportion of sublimation versus melt to the total ablation (Fig. $6 \mathrm{~b}$ and d). During the cold period, simulations considering the lowest albedo and $z_{0}$ of $1 \mathrm{~cm}$ (the reference simulation) lead to a higher sublimation rate (Fig. 6b). Indeed, a lower albedo increases the energy absorbed by the snowpack, and as the temperature is below the freezing point, this energy leads to an increase in the sublimation. A higher $z_{0}$ enhances this process even more as this leads to a more negative latent heat flux. Second, the increase of net shortwave radiation also affects the physical properties of the snowpack resulting in an increase of compaction (Fig. $4 \mathrm{~b}$ and $\mathrm{h}$ ). The snow density of the snowpack is therefore higher, which directly affects the thermal conductivity of the upper snow layers (Yen, 1981). Surface temperature variation is directly linked to the latent heat flux and therefore to sublimation, explaining the different sublimation ratios simulated depending on the albedo parameterisations and $z_{0}$ values.

In contrast to SnowModel, the albedo parameterisation in SNOWPACK does not affect the sublimation but noticeably influences the melting rate (Fig. 6c), which can be attributed to the more complex characteristics of this model. SNOWPACK allows refreezing and evaporation of melting snow within the snowpack, which can lead to a longer melt season, whereas calculated evaporation leads to a lower amount of runoff from melt. Also, SNOWPACK considers a more complex representation of snow physics, such as the grain size and microstructure, which directly impacts the albedo and can help to explain the wide diversity of melt simulations.

\section{Discussion}

\subsection{Model sensitivity and comparison}

Our results show the importance of model parameterisations and model forcing over the snow model choice, despite the limited model options chosen for the ensemble approach, and the large differences in the two model complexities chosen in this study. This conclusion, found here in an arid envi- 

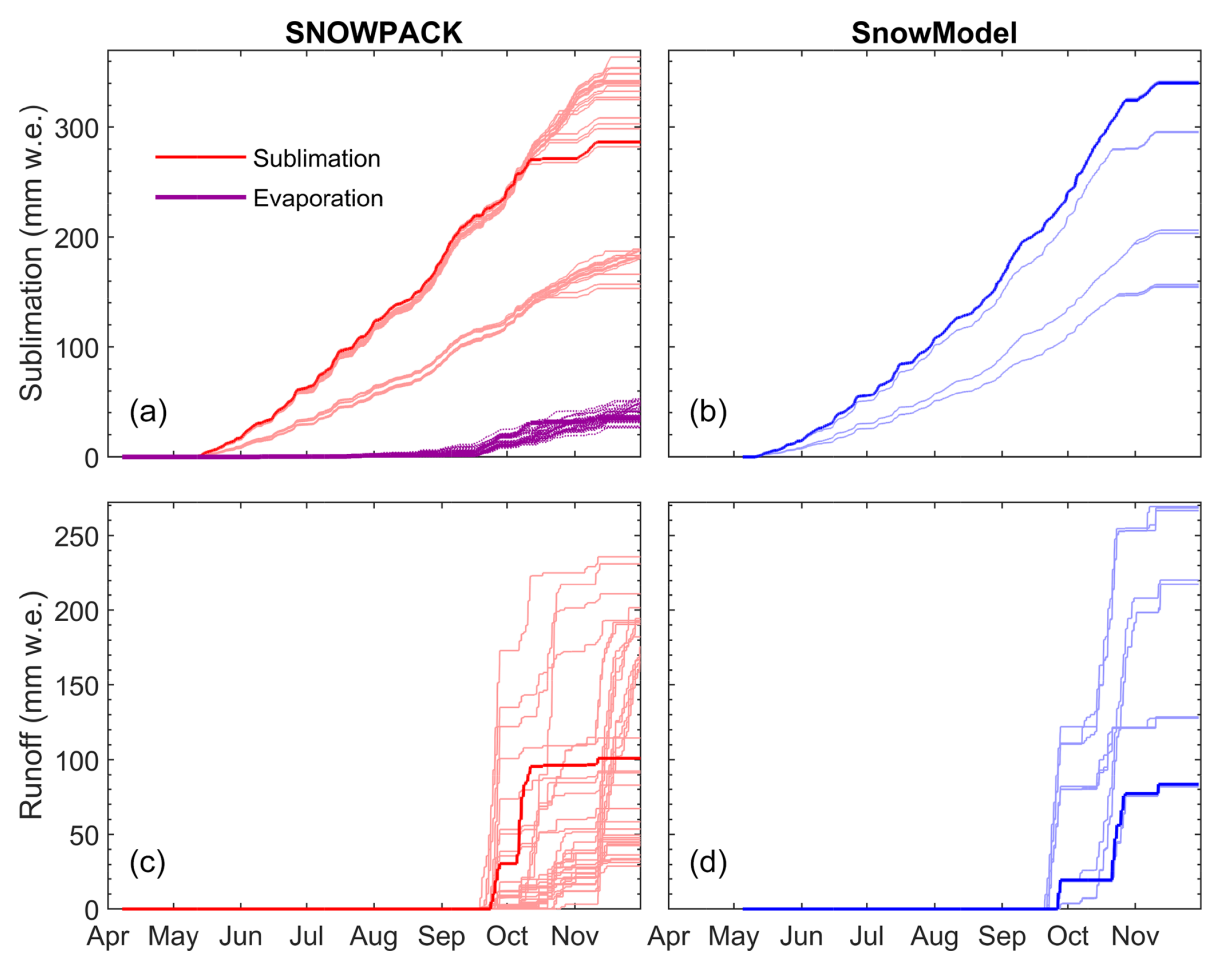

Figure 6. Cumulative sublimation (a, b) and runoff from melt (c, d) simulated by SNOWPACK (red) and SnowModel (blue). For SNOWPACK, the cumulative evaporation from melt is shown (purple lines in (a). Results for all the ensembles of parameterisations are shown and the bold lines correspond to the reference simulations of each model.

ronment, is in agreement with the studies performed in other alpine areas (Etchevers et al., 2004; Günther et al., 2019).

The representation of turbulent fluxes is an important variable to consider to simulate sublimation and in snow models this is commonly based on the bulk method; the Richardson number is often used, together with the Monin-Obukhov similarity theory, to evaluate the atmosphere stability (e.g. Liston and Hall, 1995; Vionnet et al., 2012). Here, only the Richardson number is used as both models offered this option and the uncertainty associated to the turbulent fluxes parameterisation is only considered by implementing two different $z_{0}$ values, while it can have major implications in surface energy balance modelling (e.g. Dadic et al., 2013; Conway and Cullen, 2013; Litt et al., 2017; Réveillet et al., 2020). While the stability function cannot be compared between the two models chosen in this study, the sensitivity of SNOWPACK to the six possibilities available in the current version is low (i.e. max SD bias of a few centimetres; results not shown). In a study over Brewster Glacier in New Zealand, Conway and Cullen (2013) pointed out the importance of the stability functions to properly simulate the heat fluxes with low wind speed and large temperature gradients and also that the modelled latent heat fluxes were unaffected by the choice of exchange coefficient parameterisation. The present study takes place in a dry and windy environment without a large temperature gradient and this helps to explain the small differ- ences observed related to the different atmospheric stability functions. The turbulent fluxes parameterisation is sensitive to the $z_{0}$ value and observations, such as eddy covariance measurements, are essential to accurately parameterise the turbulent fluxes (e.g. Conway and Cullen, 2013; Litt et al., 2017; Réveillet et al., 2018).

Due to the absence of such measurements, the variability of this value over time (e.g. MacDonell et al., 2013b; Pellicciotti et al., 2005; Nicholson et al., 2016) and due to other values in the literature at other locations showing a wide variety (two orders of magnitude) of snow roughness length (Gromke et al., 2011; Poggi, 1977; Bintanja and Broeke, 1995; Andreas et al., 2005), it was decided to use two different values for $z_{0}(1 \mathrm{~mm}$ and $1 \mathrm{~cm})$. Similar sensitivity ranges for SNOWPACK and SnowModel were found (e.g. Fig. 4), along with similar sublimation rates, but this directly depended on the value for $z_{0}$. For both models, a $z_{0}$ of $1 \mathrm{~cm}$ led to better simulations (Figs. 3, 4), but as applied more often, this can also be seen as optimising parameter (e.g. Stigter et al., 2018). In future work, the $z_{0}$ can be evaluated with eddy covariance measurements.

The biggest differences between the models are found as the snow settles and therefore depends on the snow density parameterisation. The challenge in this study was that the snow settling showed two distinct regimes. From May to mid-June, high compaction rates were found, whereas the 
compaction afterwards was more moderate. SNOWPACK is able to model both moderate and high compaction, depending on the parameterisation chosen, but the mode of compaction remains the same over the season. SnowModel simulates high compaction rates for all parameterisations, which is correct for the start of the season but an overestimation after mid-June. These compaction rates implicate changes in the thermal conductivity of the snowpack and thus changes in the melting. The different snow density parameterisations in SNOWPACK are still being developed and improved (e.g. Keenan et al., 2021), but an improvement of snow density parameterisations in semi-arid regions shows a demand for snow density measurements, as deriving density from SWE/SD measurements is biased over direct density observations using manual measurements (Smith et al., 2017).

Subsequently, the albedo parameterisation appears to be an important parameter to be properly assessed (Figs. 4, 6), as also reported by the studies performed in alpine regions (Etchevers et al., 2004; Zolles et al., 2019). This can be surprising at first glance as in the semi-arid Andes the ablation is mainly driven by the sublimation and the albedo parameterisation is generally crucial to accurately simulate the melt. However, according to the results presented here, the two models agree with the larger sensitivity to the albedo parameterisation. The impact of parameterisation choice differs for the two models as the uncertainty is directly related to the difference in snow physical representation and the characteristics of the models. Indeed, the range of the ensemble approach simulated by SNOWPACK is higher than that simulated by SnowModel, which is directly related to both higher number of parameterisation possibilities for SNOWPACK and more complex physical representation of the processes.

Likewise, results presented here show that the main sensitivity remains in the forcing uncertainty, in agreement with previous studies (Magnusson et al., 2015; Günther et al., 2019; Raleigh et al., 2015; Schlögl et al., 2016). For instance, Magnusson et al. (2015) found that the models of different complexity (temperature-index models versus physical models) show similar ability to reproduce daily observed snowpack runoff, and concluded that forcing uncertainties are the greatest factor affecting model performance, rather than model parameterisations. However, as mentioned by Raleigh et al. (2015), simulated SD and SWE are critically sensitive to the relative magnitude of errors in forcing. Raleigh et al. (2015) and Schlögl et al. (2016) also mentioned that precipitation bias (or correction of the undercatch of the precipitation gauge) was the most important factor, in agreement with the findings of our study.

Finally, Rutter et al. (2009) pointed out that no universal "best" model exists and model performance directly depends on calibration of the models to the specific study site. Here, similar conclusions can be drawn for both alpine and semiarid environments, namely that the choice of model structure and parameterisations, along with a specific calibration of the parameterisations for the study site, has a major impact on the performance.

\subsection{Limitations of the study and further work}

The sensitivity study of the two models to the forcing is done by adding a bias to the meteorological variables with ranges derived from the literature. It was also possible to add random noise to the data, but this does not necessarily preserve the physical consistency and would lead to low sensitivity of the models (results not shown), as random noise counterbalances each other, which has also been investigated by Raleigh et al. (2015). It would also have been possible to apply a random perturbation (e.g. Charrois et al., 2016) using a first-order auto-regressive model (Deodatis and Shinozuka, 1988). However, the forcing bias does not affect the conclusion of the relative comparison of the two models, which only requires the exact same forcing as input to be relevant. For the same reason, the choice of method applied for the forcing correction (i.e. for precipitation) and reconstruction (i.e. for the TA and RH) would not affect the conclusions of the model comparison. However, due to the precipitation uncertainty related to measurements errors and also because the sensor locations may not be representative of the area, different ways to correct the precipitation data were proposed. Günther et al. (2019) and Grünewald and Lehning (2014) already outlined that the snow cover is spatially heterogeneous even at very small scales due to topographic and microclimatic effects on accumulation, redistribution, and ablation processes, introducing an uncertainty in validation data. We also show that in any case, due to (i) the question of the sensor location representativity of the area, (ii) the precipitation undercatch because of the wind, and (iii) the high sensitivity of models to precipitation uncertainty, this study highlights the complexity and necessity of accurately measuring precipitation. Additionally, possible corrections depend on the availability of observations, but this study was restricted to not using SWE and SD as forcing, as these parameters were needed as validation data. Therefore, we chose a precipitation correction that overestimates snowfall at the start of the season, but does not capture the increase of SD and SWE in mid-June, resulting in a good agreement between simulated and observed SWE from the beginning of July (e.g. Fig. 4).

The ensemble approach with different parameterisations is built considering limited parameterisation options, contrary to other studies where a large number of physical options are considered (e.g. Essery et al., 2013; Lafaysse et al., 2017; Zolles et al., 2019). In our case, choosing snow models with different physical complexities limits the number of calibration possibilities, as the parameterisation of the same variables are chosen for the comparison. Thus, some parameterisations, such as the choice of atmospheric stability correction only available in SNOWPACK, were excluded and this model is calibrated following the same options found in SnowModel (Sect. 3.2.1). 
Testing different albedo parameterisations is chosen as (i) different options are possible in both models and (ii) previous studies concluded that the largest absolute uncertainties originate from the shortwave radiation and the albedo parameterisations (e.g. Zolles et al., 2019). The sensitivity test to different fresh snow density parameterisations was also chosen as previous studies identified this parameterisation as a significant uncertainty in model calibration (e.g. Essery et al., 2013). Finally, energy balance models are known to be sensitive to $z_{0}$, especially in cold and dry regions where sublimation is the main ablation process (e.g. Réveillet et al., 2020). However, due to this important sensitivity and the absence of measurements to properly calibrate this value, two values for $z_{0}$ were implemented, but this still might underestimate the possible range of $z_{0}$ values.

Otherwise, despite the choice of limiting the parameterisation options, SNOWPACK's sensitivity to model parameterisations is evaluated based on 40 simulations, whereas SnowModel's evaluation is based on only 12 simulations. However, the difference of the number of simulations does not impact the conclusion, as the width of the spread of different parameterisations was not quantitatively assessed.

Among the possible settings of the model, the snow transport option has not been activated, while the option is available in both models. However, due to the strong wind speed characteristics of the study area (Gascoin et al., 2013, and Fig. 2), snow transport is expected to be considerable. Yet, snow transport estimation remains out of the scope of this study, which was focused on energy balance comparisons mainly to assess differences in sublimation rates. Also, in a study performed in the Pascua-Lama catchment, a region to the north of Tapado AWS, Gascoin et al. (2013) highlighted that the inclusion of SnowTran3D does not change the fact that the model is unable to capture the small-scale snow depth spatial variability (as captured by in situ snow depth sensors). Finally, snow transport in SNOWPACK can only be simulated in the three-dimensional domain with SD as forcing, which then could not be used as validation data. However, due to the importance and complexity of modelling snow transport, properly assessing its impact could be assessed in future work.

\section{Conclusions}

Snow models are key to quantifying runoff and providing accurate water availability projections. The aim of this study was to compare two snow models, SNOWPACK and SnowModel, and evaluate their sensitivity relative to parameterisation and forcing. The two models were run over the 2017 snow season, at local point, and forced with (i) the most ideal set of input parameters, (ii) an ensemble of different physical parameterisations, and (iii) an ensemble of biased forcing.

The most ideal set of input parameters consisted of observed forcing and the validation parameters (SD and $S_{\downarrow}$ for SNOWPACK; SWE for SnowModel) given as input. Hence, the models were able to assimilate the forced precipitation to correct for undercatch in the precipitation gauge. SNOWPACK is able to approach the observation very well (i.e. $\min$. RMSE of $9.2 \mathrm{~cm}$, $\max . R^{2}$ of 0.93 , calculated with the observed and simulated SD), but SnowModel only adjusts the precipitation at two precipitation events, still leading to undercatch. The final correction of the precipitation data was done with an equation based on TA and WS, as it was unwanted to adjust the precipitation with SNOWPACK's assimilated data, as these assimilated data are built from data that were required for model evaluation. The parameterisation simulations were done considering different parameterisations of the albedo and the fresh snow density and different values for $z_{0}$. The results indicated a significant difference related mainly to the parameterisation choice of the albedo and $z_{0}$. However, the impact of the albedo affects the two models differently. For SnowModel, the albedo parameterisation has a significant impact on the simulated sublimation during the cold period while SNOWPACK simulates similar sublimation rates for all the possible parameterisations. The choice of albedo parameterisation in SNOWPACK has direct consequences on melt at the end of the season. The model differences are mainly related to the model characteristics (e.g. the consideration of the water evaporation and refreezing into the snowpack) and the more complex representation of the snow physics in SNOWPACK. However, the models are both sensitive to the chosen $z_{0}$, leading to sublimation rates ranging from $36 \%$ up to $86 \%$ of total ablation.

In addition, the results presented in this study highlight a larger uncertainty depending on the model parameterisation (despite the limited number of options chosen) than between the two models (despite the significant differences in their physical complexity).

Otherwise, for both models, results show high levels of uncertainty related to forcings, which is directly related to the bias chosen, but the spread of the uncertainty for both models is approximately the same. SNOWPACK and SnowModel are highly influenced by precipitation uncertainties. Both models show similar levels of uncertainty in modelling the end of the season.

Our study covers the winter season of 2017, and our conclusions on model sensitivity to various parameterisations are specific to that period. In further studies, simulations could be performed over a larger time period and at distinct places to complement our results. Furthermore, additional models could be used, in particular snow models with similar physical complexity. Such work would provide additional information of the parameterisation sensitivity by allowing a comparison based on a larger choice of possible parameterisations.

Data availability. SnowModel can be accessed by contacting the administrator, Glen E. Liston. SNOWPACK is an Open Source 
model and can be accessed at https://gitlabext.wsl.ch/snowmodels/snowpack (last access: 31 August 2021). Parts of the data used in this paper (AWS data) can be accessed at http://www.ceazamet.cl/index.php?e_cod=TPF\&pag=mod_estacion (last access: 31 August 2021, CEAZAmet, 2021). For any other access to the data presented in this study, please contact the authors.

Supplement. The supplement related to this article is available online at: https://doi.org/10.5194/tc-15-4241-2021-supplement.

Author contributions. AV conducted data preparation, ran the numerical experiments, and produced the figures. AV and MR designed the modelling strategy. MR and SM designed the study. All authors contributed to the results analysis and to the preparation of the paper.

Competing interests. The authors declare that they have no conflict of interest.

Disclaimer. Publisher's note: Copernicus Publications remains neutral with regard to jurisdictional claims in published maps and institutional affiliations.

Acknowledgements. We thank Michael Lehning and two anonymous referees as well as the editor, Brice Noël, for their constructive comments, which helped to sharpen the scope of this study. We also thank Glen E. Liston for providing the code of SnowModel and are grateful to CEAZAmet and the CEAZA glaciology group for maintaining the Tapado AWS and the data centre.

Financial support. Marion Réveillet and Shelley MacDonell were supported by CONICYT-Programa Regional R16A10003, and the Coquimbo regional government (grant no. FIC-R(2015) BIP 30403127-0). Marion Réveillet was also supported by the ANR program (grant no. ANR-16-CE01-0006 EBONI).

Review statement. This paper was edited by Brice Noël and reviewed by Michael Lehning and two anonymous referees.

\section{References}

Andreas, E. L., Jordan, R. E., and Makshtas, A. P.: Parameterizing turbulent exchange over sea ice: the ice station weddell results, Bound.-Lay. Meteorol., 114, 439-460, https://doi.org/10.1007/s10546-004-1414-7, 2005.

Ayala, A., Pellicciotti, F., Peleg, N., and Burlando, P.: Melt and surface sublimation across a glacier in a dry environment: distributed energy-balance modelling of Juncal Norte Glacier, Chile, J. Glaciol., 63, 803-822, https://doi.org/10.1017/jog.2017.46, 2017.
Bartelt, P. and Lehning, M.: A physical SNOWPACK model for the Swiss avalanche warning: Part I: Numerical model, Cold Reg. Sci. Technol., 35, 123-145, https://doi.org/10.1016/s0165232x(02)00074-5, 2002.

Bavay, M. and Egger, T.: MeteoIO 2.4.2: a preprocessing library for meteorological data, Geosci. Model Dev., 7, 3135-3151, https://doi.org/10.5194/gmd-7-3135-2014, 2014.

Bintanja, R. and Broeke, M. R. V. D.: Momentum and scalar transfer coefficients over aerodynamically smooth antarctic surfaces, Bound.-Lay. Meteorol., 74, 89-111, https://doi.org/10.1007/bf00715712, 1995.

Blandford, T. R., Humes, K. S., Harshburger, B. J., Moore, B. C., Walden, V. P., and Ye, H.: Seasonal and Synoptic Variations in Near-Surface Air Temperature Lapse Rates in a Mountainous Basin, J. Appl. Meteorol. Climatol., 47, 249-261, https://doi.org/10.1175/2007jamc1565.1, 2008.

Braithwaite, R. J. and Olesen, O. B.: Calculation of Glacier Ablation from Air Temperature, West Greenland, in: Glaciology and Quaternary Geology, Springer, the Netherlands, 219-233, https://doi.org/10.1007/978-94-015-7823-3_15, 1989.

Brock, B. W., Willis, I. C., and Sharp, M. J.: Measurement and parameterization of albedo variations at Haut Glacier d'Arolla, Switzerland, J. Glaciol., 46, 675-688, https://doi.org/10.3189/172756500781832675, 2000.

Brock, B. W., Willis, I. C., and Sharp, M. J.: Measurement and parameterization of aerodynamic roughness length variations at Haut Glacier d'Arolla, Switzerland, J. Glaciol., 52, 281-297, https://doi.org/10.3189/172756506781828746, 2006.

CEAZAmet: Estación El Tapado, available at: http://www. ceazamet.cl/index.php?pag=mod_estacion\&e_cod=TPF, last access: 31 August 2021.

Charrois, L., Cosme, E., Dumont, M., Lafaysse, M., Morin, S., Libois, Q., and Picard, G.: On the assimilation of optical reflectances and snow depth observations into a detailed snowpack model, The Cryosphere, 10, 1021-1038, https://doi.org/10.5194/tc-10-1021-2016, 2016.

Conway, J. P. and Cullen, N. J.: Constraining turbulent heat flux parameterization over a temperate maritime glacier in New-Zealand, Ann. Glaciol., 54, 41-51, https://doi.org/10.3189/2013aog63a604, 2013.

Cuffey, K. M. and Paterson, W. S. B.: The Physics of Glaciers, Elsevier LTD, Oxford, ISBN 0123694612, 704 pp., 2010.

Dadic, R., Mott, R., Lehning, M., Carenzo, M., Anderson, B., and Mackintosh, A.: Sensitivity of turbulent fluxes to wind speed over snow surfaces in different climatic settings, Adv. Water Resour., 55, 178-189, https://doi.org/10.1016/j.advwatres.2012.06.010, 2013.

Deodatis, G. and Shinozuka, M.: Auto-Regressive Model for Nonstationary Stochastic Processes, J. Eng. Mech., 114, 1995-2012, https://doi.org/10.1061/(asce)0733-9399(1988)114:11(1995), 1988.

Douville, H., Royer, J.-F., and Mahfouf, J.-F.: A new snow parameterization for the Météo-France climate model. Part I: validation in stand-alone experiments, Clim. Dynam., 12, 21-35, https://doi.org/10.1007/BF00208760, 1995.

Dutra, E., Balsamo, G., Viterbo, P., Miranda, P. M. A., Beljaars, A., Schär, C., and Elder, K.: An Improved Snow Scheme for the ECMWF Land Surface Model: Descrip- 
tion and Offline Validation, J. Hydrometeorol., 11, 899-916, https://doi.org/10.1175/2010jhm1249.1, 2010.

Essery, R.: A factorial snowpack model (FSM 1.0), Geosci. Model Dev., 8, 3867-3876, https://doi.org/10.5194/gmd-8-3867-2015, 2015.

Essery, R., Morin, S., Lejeune, Y., and Ménard, C. B.: A comparison of 1701 snow models using observations from an alpine site, Adv. Water Resour., 55, 131-148, https://doi.org/10.1016/j.advwatres.2012.07.013, 2013.

Etchevers, P., Martin, E., Brown, R., Fierz, C., Lejeune, Y., Bazile, E., Boone, A., Dai, Y.-J., Essery, R., Fernandez, A., Gusev, Y., Jordan, R., Koren, V., Kowalczyk, E., Nasonova, N. O., Pyles, R. D., Schlosser, A., Shmakin, A. B., Smirnova, T. G., Strasser, U., Verseghy, D., Yamazaki, T., and Yang, Z.-L.: Validation of the energy budget of an alpine snowpack simulated by several snow models (Snow MIP project), Ann. Glaciol., 38, 150-158, https://doi.org/10.3189/172756404781814825, 2004.

Favier, V., Falvey, M., Rabatel, A., Praderio, E., and López, D.: Interpreting discrepancies between discharge and precipitation in high-altitude area of Chile's Norte Chico region $\left(26-32^{\circ} \mathrm{S}\right)$, Water Resour. Res., 45, W02424, https://doi.org/10.1029/2008wr006802, 2009.

Gascoin, S., Lhermitte, S., Kinnard, C., Bortels, K., and Liston, G. E.: Wind effects on snow cover in PascuaLama, Dry Andes of Chile, Adv. Water Resour., 55, 25-39, https://doi.org/10.1016/j.advwatres.2012.11.013, 2013.

Gromke, C., Manes, C., Walter, B., Lehning, M., and Guala, M.: Aerodynamic Roughness Length of Fresh Snow, Bound.Lay. Meteorol., 141, 21-34, https://doi.org/10.1007/s 10546-0119623-3, 2011.

Grünewald, T. and Lehning, M.: Are flat-field snow depth measurements representative? A comparison of selected index sites with areal snow depth measurements at the small catchment scale, Hydrol. Process., 29, 1717-1728, https://doi.org/10.1002/hyp.10295, 2014.

Günther, D., Marke, T., Essery, R., and Strasser, U.: Uncertainties in Snowpack Simulations - Assessing the Impact of Model Structure, Parameter Choice, and Forcing Data Error on Point-Scale Energy Balance Snow Model Performance, Water Resour. Res., 55, 2779-2800, https://doi.org/10.1029/2018wr023403, 2019.

Hock, R.: Temperature index melt modelling in mountain areas, J. Hydrol., 282, 104-115, https://doi.org/10.1016/s00221694(03)00257-9, 2003.

Keenan, E., Wever, N., Dattler, M., Lenaerts, J. T. M., Medley, B., Kuipers Munneke, P., and Reijmer, C.: Physics-based SNOWPACK model improves representation of near-surface Antarctic snow and firn density, The Cryosphere, 15, 1065-1085, https://doi.org/10.5194/tc-15-1065-2021, 2021.

Krinner, G., Derksen, C., Essery, R., Flanner, M., Hagemann, S., Clark, M., Hall, A., Rott, H., Brutel-Vuilmet, C., Kim, H., Ménard, C. B., Mudryk, L., Thackeray, C., Wang, L., Arduini, G., Balsamo, G., Bartlett, P., Boike, J., Boone, A., Chéruy, F., Colin, J., Cuntz, M., Dai, Y., Decharme, B., Derry, J., Ducharne, A., Dutra, E., Fang, X., Fierz, C., Ghattas, J., Gusev, Y., Haverd, V., Kontu, A., Lafaysse, M., Law, R., Lawrence, D., Li, W., Marke, T., Marks, D., Ménégoz, M., Nasonova, O., Nitta, T., Niwano, M., Pomeroy, J., Raleigh, M. S., Schaedler, G., Semenov, V., Smirnova, T. G., Stacke, T., Strasser, U., Svenson, S., Turkov, D., Wang, T., Wever, N., Yuan, H., Zhou, W., and Zhu, D.:
ESM-SnowMIP: assessing snow models and quantifying snowrelated climate feedbacks, Geosci. Model Dev., 11, 5027-5049, https://doi.org/10.5194/gmd-11-5027-2018, 2018.

Lafaysse, M., Cluzet, B., Dumont, M., Lejeune, Y., Vionnet, V., and Morin, S.: A multiphysical ensemble system of numerical snow modelling, The Cryosphere, 11, 1173-1198, https://doi.org/10.5194/tc-11-1173-2017, 2017.

Lehning, M., Bartelt, P., Brown, B., and Fierz, C.: A physical SNOWPACK model for the Swiss avalanche warning: Part III: Meteorological forcing, thin layer formation and evaluation, Cold Reg. Sci. Technol., 35, 169-184, https://doi.org/10.1016/s0165-232x(02)00072-1, 2002a.

Lehning, M., Bartelt, P., Brown, B., Fierz, C., and Satyawali, P.: A physical SNOWPACK model for the Swiss avalanche warning: Part II: Snow microstructure, Cold Reg. Sci. Technol., 35, 147167, https://doi.org/10.1016/s0165-232x(02)00073-3, $2002 \mathrm{~b}$.

Lehning, M., Völksch, I., Gustafsson, D., Nguyen, T. A., Stähli, M., and Zappa, M.: ALPINE3D: a detailed model of mountain surface processes and its application to snow hydrology, Hydrol. Process., 20, 2111-2128, https://doi.org/10.1002/hyp.6204, 2006.

Liston, G. E. and Elder, K.: A Meteorological Distribution System for High-Resolution Terrestrial Modeling (MicroMet), J. Hydrometeorol., 7, 217-234, https://doi.org/10.1175/jhm486.1, 2006a.

Liston, G. E. and Elder, K.: A Distributed Snow-Evolution Modeling System (SnowModel), J. Hydrometeorol., 7, 1259-1276, https://doi.org/10.1175/jhm548.1, 2006b.

Liston, G. E. and Hall, D. K.: An energy-balance model of lake-ice evolution, J. Glaciol., 41, 373-382, https://doi.org/10.3189/s0022143000016245, 1995.

Liston, G. E. and Sturm, M.: A snow-transport model for complex terrain, J. Glaciol., 44, 498-516, https://doi.org/10.3189/s0022143000002021, 1998.

Litt, M., Sicart, J.-E., Six, D., Wagnon, P., and Helgason, W. D.: Surface-layer turbulence, energy balance and links to atmospheric circulations over a mountain glacier in the French Alps, The Cryosphere, 11, 971-987, https://doi.org/10.5194/tc11-971-2017, 2017.

MacDonald, J. and Pomeroy, J.: Gauge undercatch of two common snowfall gauges in a prairie environment, in: Proceedings of the 64th Eastern Snow Conference, 29, 119-126, 2007.

MacDonell, S., Kinnard, C., Mölg, T., Nicholson, L., and Abermann, J.: Meteorological drivers of ablation processes on a cold glacier in the semi-arid Andes of Chile, The Cryosphere, 7, 1513-1526, https://doi.org/10.5194/tc-7-1513-2013, 2013a.

MacDonell, S., Nicholson, L., and Kinnard, C.: Parameterisation of incoming longwave radiation over glacier surfaces in the semi-arid Andes of Chile, Theor. Appl. Climatol., 111, 513-528, https://doi.org/10.1007/s00704-012-0675-1, 2013b.

Magnusson, J., Wever, N., Essery, R., Helbig, N., Winstral, A., and Jonas, T.: Evaluating snow models with varying process representations for hydrological applications, Water Resour. Res., 51, 2707-2723, https://doi.org/10.1002/2014wr016498, 2015.

Menard, C. B., Essery, R., Krinner, G., Arduini, G., Bartlett, P., Boone, A., Brutel-Vuilmet, C., Burke, E., Cuntz, M., Dai, Y., Decharme, B., Dutra, E., Fang, X., Fierz, C., Gusev, Y., Hagemann, S., Haverd, V., Kim, H., Lafaysse, M., Marke, T., Nasonova, O., Nitta, T., Niwano, M., Pomeroy, J., Schädler, G., Se- 
menov, V. A., Smirnova, T., Strasser, U., Swenson, S., Turkov, D., Wever, N., and Yuan, H.: Scientific and Human Errors in a Snow Model Intercomparison, B. Am. Meteorol. Soc., 102, E61E79, https://doi.org/10.1175/bams-d-19-0329.1, 2021.

Mengual Henríquez, S. A.: Caracterización de la nieve de distintas localidades de Chile mediante el uso del modelo SNOWPACK, Master's thesis, Universidad de Chile, Santiago de Chile, 2017.

Nicholson, L. I., Pętlicki, M., Partan, B., and MacDonell, S.: 3-D surface properties of glacier penitentes over an ablation season, measured using a Microsoft Xbox Kinect, The Cryosphere, 10, 1897-1913, https://doi.org/10.5194/tc-10-1897-2016, 2016.

Oke, T. R.: Boundary layer climates, Routledge, London, https://doi.org/10.4324/9780203407219, 2002.

Pellicciotti, F., Brock, B., Strasser, U., Burlando, P., Funk, M., and Corripio, J.: An enhanced temperature-index glacier melt model including the shortwave radiation balance: development and testing for Haut Glacier d'Arolla, Switzerland, J. Glaciol., 51, 573587, https://doi.org/10.3189/172756505781829124, 2005.

Poggi, A.: Heat Balance in the Ablation Area of the Ampere Glacier (Kerguelen Islands), J. Appl. Meteorol., $\quad 16, \quad 48-55, \quad \mathrm{https}: / /$ doi.org/10.1175/15200450(1977)016<0048:hbitaa>2.0.co;2, 1977.

Rabatel, A., Castebrunet, H., Favier, V., Nicholson, L., and Kinnard, C.: Glacier changes in the Pascua-Lama region, Chilean Andes $\left(29^{\circ} \mathrm{S}\right)$ : recent mass balance and $50 \mathrm{yr}$ surface area variations, The Cryosphere, 5, 1029-1041, https://doi.org/10.5194/tc5-1029-2011, 2011.

Raleigh, M. S., Lundquist, J. D., and Clark, M. P.: Exploring the impact of forcing error characteristics on physically based snow simulations within a global sensitivity analysis framework, Hydrol. Earth Syst. Sci., 19, 3153-3179, https://doi.org/10.5194/hess-19-3153-2015, 2015.

Réveillet, M., Six, D., Vincent, C., Rabatel, A., Dumont, M., Lafaysse, M., Morin, S., Vionnet, V., and Litt, M.: Relative performance of empirical and physical models in assessing the seasonal and annual glacier surface mass balance of SaintSorlin Glacier (French Alps), The Cryosphere, 12, 1367-1386, https://doi.org/10.5194/tc-12-1367-2018, 2018.

Réveillet, M., MacDonell, S., Gascoin, S., Kinnard, C., Lhermitte, S., and Schaffer, N.: Impact of forcing on sublimation simulations for a high mountain catchment in the semiarid Andes, The Cryosphere, 14, 147-163, https://doi.org/10.5194/tc14-147-2020, 2020.

Rutter, N., Essery, R., Pomeroy, J., Altimir, N., Andreadis, K., Baker, I., Barr, A., Bartlett, P., Boone, A., Deng, H., Douville, H., Dutra, E., Elder, K., Ellis, C., Feng, X., Gelfan, A., Goodbody, A., Gusev, Y., Gustafsson, D., Hellström, R., Hirabayashi, Y., Hirota, T., Jonas, T., Koren, V., Kuragina, A., Lettenmaier, D., Li, W.-P., Luce, C., Martin, E., Nasonova, O., Pumpanen, J., Pyles, R. D., Samuelsson, P., Sandells, M., Schädler, G., Shmakin, A., Smirnova, T. G., Stähli, M., Stöckli, R., Strasser, U., Su, H., Suzuki, K., Takata, K., Tanaka, K., Thompson, E., Vesala, T., Viterbo, P., Wiltshire, A., Xia, K., Xue, Y., and Yamazaki, T.: Evaluation of forest snow processes models (SnowMIP2), J. Geophys. Res., 114, https://doi.org/10.1029/2008jd011063, 2009.

Scaff, L., Rutllant, J. A., Rahn, D., Gascoin, S., and Rondanelli, R.: Meteorological Interpretation of Orographic Precipitation Gradients along an Andes West Slope Basin at $30^{\circ} \mathrm{S}$ (Elqui Valley, Chile), J. Hydrometeorol., 18, 713-727, https://doi.org/10.1175/jhm-d-16-0073.1, 2017.

Schlögl, S., Marty, C., Bavay, M., and Lehning, M.: Sensitivity of Alpine3D modeled snow cover to modifications in DEM resolution, station coverage and meteorological input quantities, Environ. Model. Softw., 83, 387-396, https://doi.org/10.1016/j.envsoft.2016.02.017, 2016.

Schmucki, E., Marty, C., Fierz, C., and Lehning, M.: Evaluation of modelled snow depth and snow water equivalent at three contrasting sites in Switzerland using SNOWPACK simulations driven by different meteorological data input, Cold Reg. Sci. Technol., 99, 27-37, https://doi.org/10.1016/j.coldregions.2013.12.004, 2014.

Smith, C. D.: Correcting the wind bias in snowfall measurements made with a Geonor T-200B precipitation gauge and alter wind shield, in: 87th American Meteorological Society Annual Meeting, San Antonio, TX, 2007.

Smith, C. D., Kontu, A., Laffin, R., and Pomeroy, J. W.: An assessment of two automated snow water equivalent instruments during the WMO Solid Precipitation Intercomparison Experiment, The Cryosphere, 11, 101-116, https://doi.org/10.5194/tc11-101-2017, 2017.

Stigter, E. E., Litt, M., Steiner, J. F., Bonekamp, P. N. J., Shea, J. M., Bierkens, M. F. P., and Immerzeel, W. W.: The Importance of Snow Sublimation on a Himalayan Glacier, Front. Earth Sci., 6, 108, https://doi.org/10.3389/feart.2018.00108, 2018.

Strack, J. E., Liston, G. E., and Pielke Sr., R. A.: Modeling snow depth for improved simulation of snow-vegetation-atmosphere interactions, J. Hydrometeorol., 5, 723-734, 2004.

Strasser, U. and Marke, T.: ESCIMO.spread - a spreadsheetbased point snow surface energy balance model to calculate hourly snow water equivalent and melt rates for historical and changing climate conditions, Geosci. Model Dev., 3, 643-652, https://doi.org/10.5194/gmd-3-643-2010, 2010.

Vionnet, V., Brun, E., Morin, S., Boone, A., Faroux, S., Le Moigne, P., Martin, E., and Willemet, J.-M.: The detailed snowpack scheme Crocus and its implementation in SURFEX v7.2, Geosci. Model Dev., 5, 773-791, https://doi.org/10.5194/gmd-5773-2012, 2012.

Weiser, U., Olefs, M., Schöner, W., Weyss, G., and Hynek, B.: Correction of broadband snow albedo measurements affected by unknown slope and sensor tilts, The Cryosphere, 10, 775-790, https://doi.org/10.5194/tc-10-775-2016, 2016.

Wever, N., Fierz, C., Mitterer, C., Hirashima, H., and Lehning, M.: Solving Richards Equation for snow improves snowpack meltwater runoff estimations in detailed multi-layer snowpack model, The Cryosphere, 8, 257-274, https://doi.org/10.5194/tc-8-2572014, 2014.

Wolff, M. A., Isaksen, K., Petersen-Øverleir, A., Ødemark, K., Reitan, T., and Brækkan, R.: Derivation of a new continuous adjustment function for correcting wind-induced loss of solid precipitation: results of a Norwegian field study, Hydrol. Earth Syst. Sci., 19, 951-967, https://doi.org/10.5194/hess-19-951-2015, 2015.

Wright, M.: Performance Analysis of CS725 Snow Water Equivalent Sensor, Campbell Scientific Corp, Edmonton, AB, 2011.

Yen, Y.-C.: Review of thermal properties of snow, ice, and sea ice, vol. 81, US Army, Corps of Engineers, Cold Regions Research and Engineering Laboratory, Hanover, New Hampshire, USA, 1981. 
Zolles, T., Maussion, F., Galos, S. P., Gurgiser, W., and Nicholson, L.: Robust uncertainty assessment of the spatio-temporal transferability of glacier mass and energy balance models, The Cryosphere, 13, 469-489, https://doi.org/10.5194/tc-13469-2019, 2019. 